\title{
THE MADISON SQUARE GARDEN DISPERSION STUDY (MSG05) METEOROLOGICAL DATA DESCRIPTION
}

R. M. Reynolds

October 2006

\author{
Environmental Sciences Department \\ Environmental Research \& Technology Division \\ Brookhaven National Laboratory \\ P.O. Box 5000 \\ Upton, NY 11973-5000 \\ www.bnl.gov
}

Notice: This manuscript has been authored by employees of Brookhaven Science Associates, LLC under Contract No. DE-AC0298CH10886 with the U.S. Department of Energy. The publisher by accepting the manuscript for publication acknowledges that the United States Government retains a non-exclusive, paid-up, irrevocable, world-wide license to publish or reproduce the published form of this manuscript, or allow others to do so, for United States Government purposes. 


\section{DISCLAIMER}

This report was prepared as an account of work sponsored by an agency of the United States Government. Neither the United States Government nor any agency thereof, nor any of their employees, nor any of their contractors, subcontractors, or their employees, makes any warranty, express or implied, or assumes any legal liability or responsibility for the accuracy, completeness, or any third party's use or the results of such use of any information, apparatus, product, or process disclosed, or represents that its use would not infringe privately owned rights. Reference herein to any specific commercial product, process, or service by trade name, trademark, manufacturer, or otherwise, does not necessarily constitute or imply its endorsement, recommendation, or favoring by the United States Government or any agency thereof or its contractors or subcontractors. The views and opinions of authors expressed herein do not necessarily state or reflect those of the United States Government or any agency thereof. 


\section{THE MADISON SQUARE GARDEN DISPERSION STUDY (MSG05) METEOROLOGICAL DATA DESCRIPTION}

\section{R. Michael Reynolds ${ }^{1}$ Brookhaven National Laboratory}

\section{Abstract}

MSG05 was a study of atmospheric transport and dispersion in the deep urban canyons of Midtown New York City, in the area of Madison Square Garden. This downtown area is considered to be a prime target for terrorist activities, and has one of the largest commuter populations in the world. Little is known about air flow and hazardous gas dispersion in such scenarios, since previous urban field experiments have focused on small to medium sized cities with much smaller street canyons.

On March 10 and 14, 2005, a series of Perfluorocarbon Tracer (PFT) tracers were released and tracked with about 30 sampling stations at radial distances of about 0.2 and $0.4 \mathrm{~km}$, with vertical profiles near a $250 \mathrm{~m}$ tall building (One Penn Plaza). Meteorological stations collected wind data in the MSG vicinity, at street level and rooftop level. MSG05 is expected to provide useful information on rapid vertical dispersion will assist in planning for more extensive studies.

This data release is being made available to a restricted group of key scientists who have worked on the project. Part of the QA program involves feedback from scientists and modelers who are working on this study. This document describes the meteorological component of the project. The file organization and metadata are detailed so that a researcher can work with the data sets.

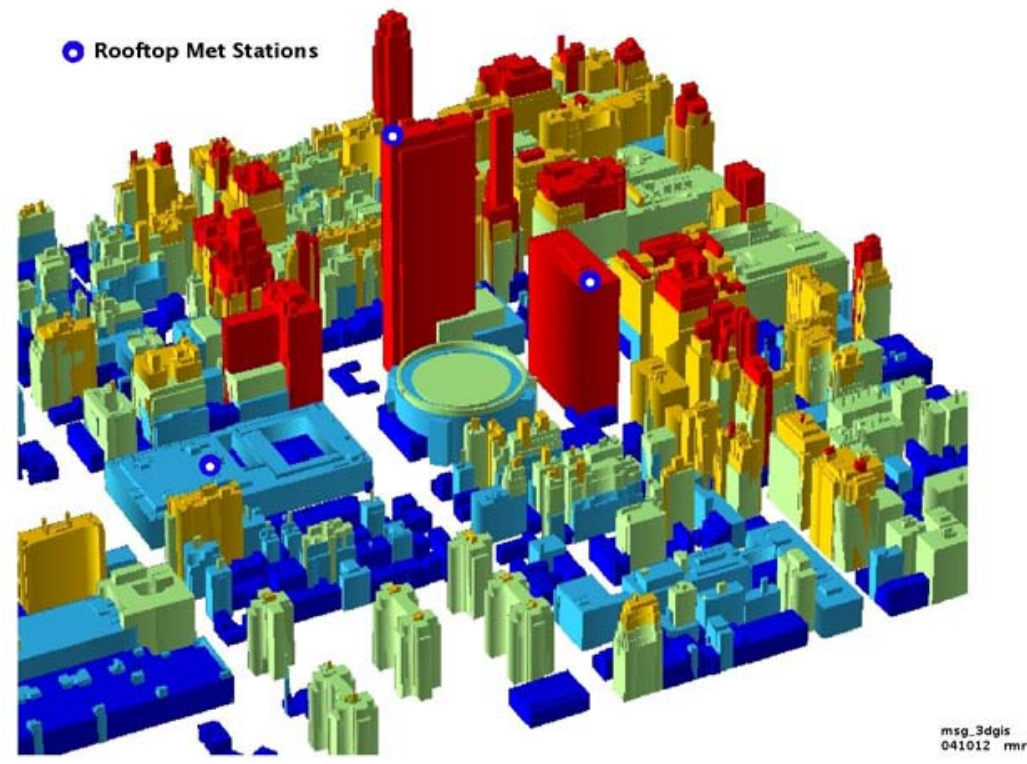

Data from Vexcel Inc. Figure was provided by Austen Ivey, LANL, Sep 2004

${ }^{1}$ The meteorological team is listed on page 32 


\section{The Madison Square Garden Dispersion Study (MSG-05) Meteorological Data Report}

R. Michael Reynolds

Brookhaven National Laboratory

January 4, 2006

\section{Contents}

1 Introduction $\quad 5$

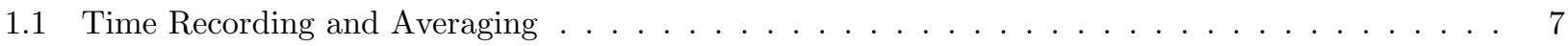

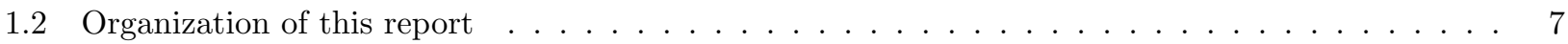

2 Data Organization $r$

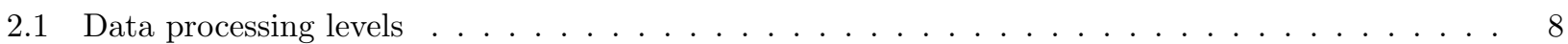

2.2 Identification Codes $\ldots \ldots \ldots \ldots \ldots \ldots \ldots \ldots \ldots$

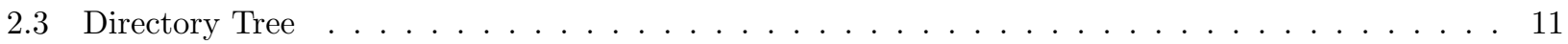

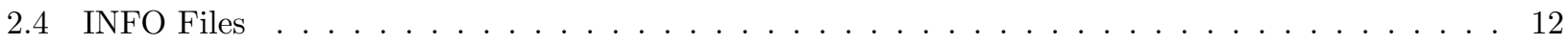

3 Locations $\quad 12$

4 Instruments $\quad 14$

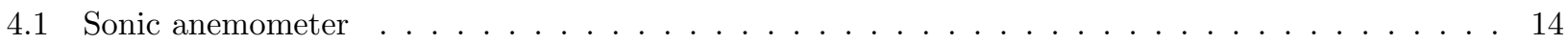

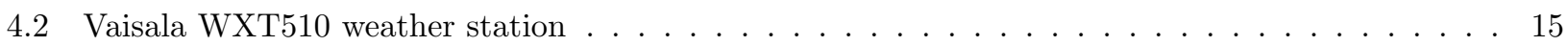

4.3 Tripod towers and setback frames $\ldots \ldots \ldots \ldots \ldots \ldots \ldots$

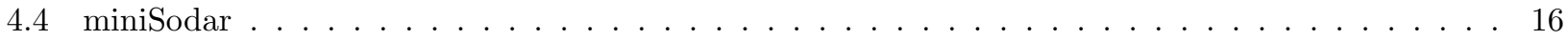

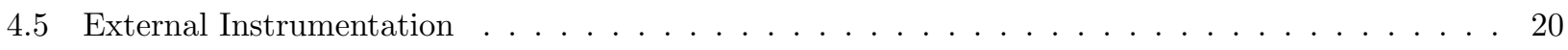

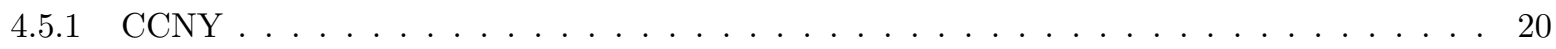

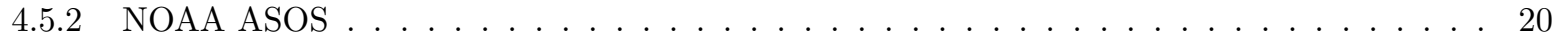

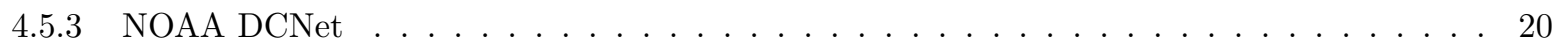

4.5 .4 Stevens Institute of Technology . . . . . . . . . . . . . . . . . . . 20

5 MSG Deployment Procedures $\quad 21$

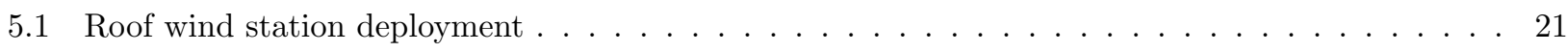

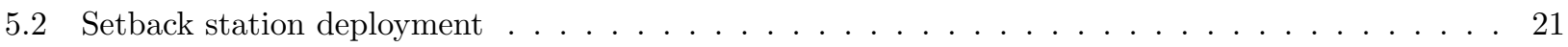

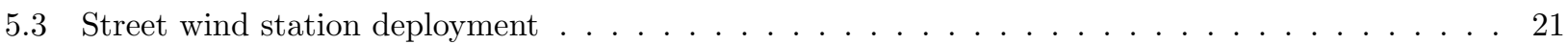


5.4 Sodar Installation and Operation $\ldots \ldots \ldots \ldots \ldots \ldots \ldots \ldots \ldots \ldots$

6 Data Sets 22

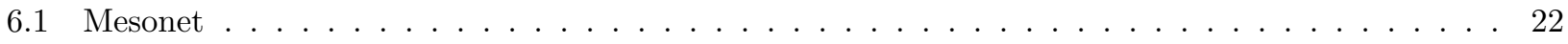

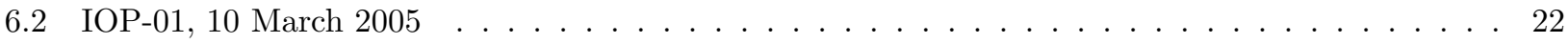

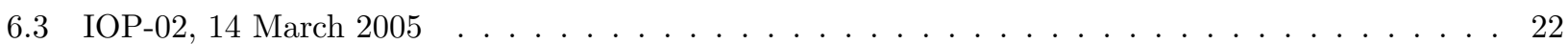

7 Data Processing $\quad 22$

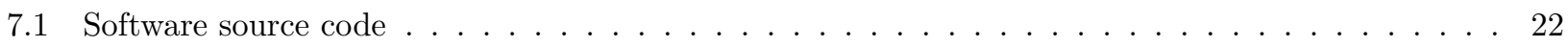

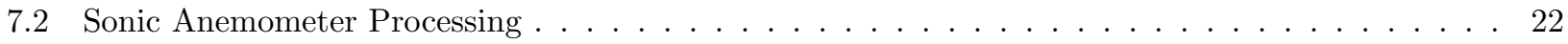

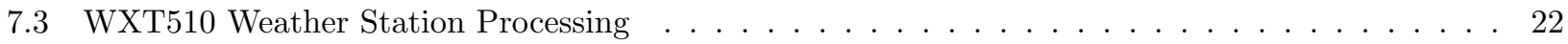

7.4 miniSodar Data Processing . . . . . . . . . . . . . . . . . . . . . . 22

8 Quality Assurance and Data Uncertainty 25

$8.13 \mathrm{D}$ sonic and WXT comparisons at two street stations $\ldots \ldots \ldots \ldots \ldots \ldots$

8.2 Post Experiment Field Intercomparisons ～. . . . . . . . . . . . . . . . . . . . . . . 29

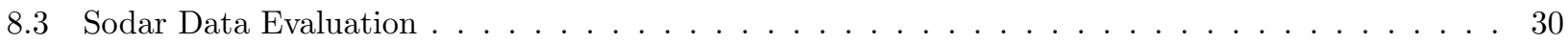

9 Acknowledgements $\quad 32$

10 References $\quad 33$

$\begin{array}{ll}\text { A R. M. Young Model } 81000 \text { 3D Sonic Anemometer } & 34\end{array}$

$\begin{array}{ll}\text { В WXT510 } & 35\end{array}$

$\begin{array}{lr}\text { C SODAR Raw Data Block } & 37\end{array}$

$\begin{array}{ll}\text { D Sodar Header Information } & 38\end{array}$ 


\section{List of Figures}

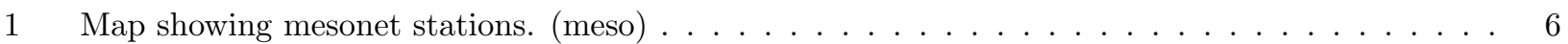

2 Locations of MSG-05 meteorological stations. (msgsites) $\ldots \ldots \ldots \ldots \ldots \ldots$

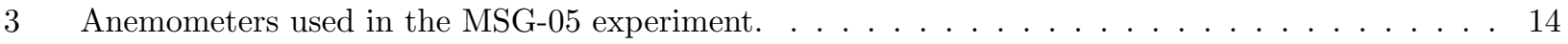

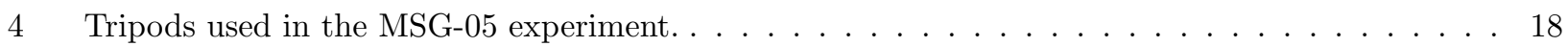

5 The setback station S6 on the New Yorker Hotel Overhang. . . . . . . . . . . . . . . . 18

6 A miniSodar on the Farley Post Office roof during the MSG-05 experiment. (minisodar) . . . . . 19

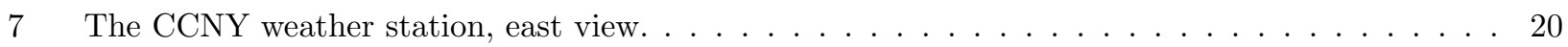

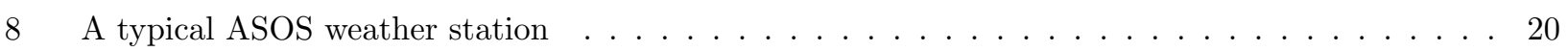

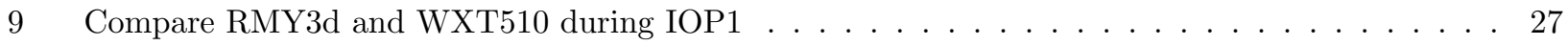

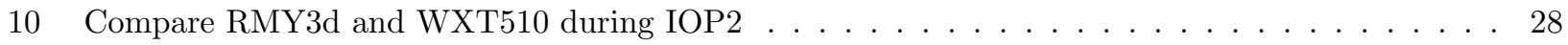

11 Mean wind speeds during the field intercomparison. . . . . . . . . . . . . . . . . . 29

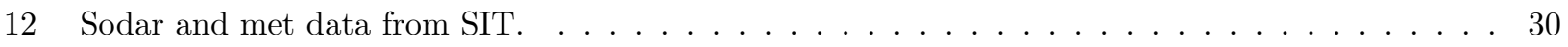

13 Sodar and met data from Farley Post Office. . . . . . . . . . . . . . . . . . . 31

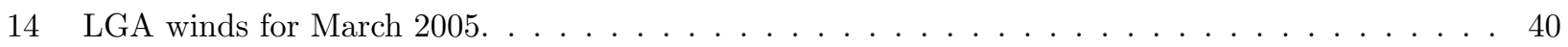

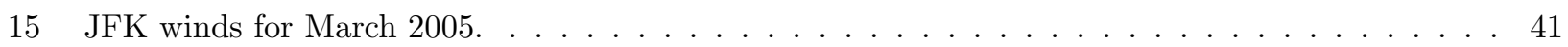

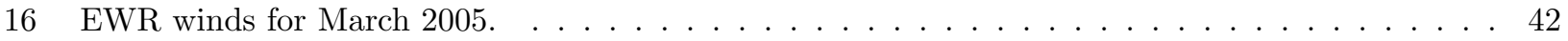

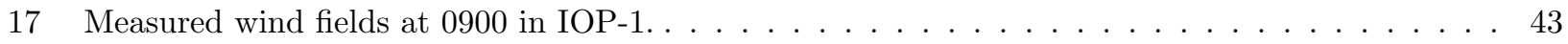

18 Measured wind fields at 0900 in IOP- $\ldots \ldots \ldots \ldots \ldots \ldots \ldots$ 


\section{Introduction}

The Madison Square Garden Dispersion Experiment (MSG-05) took place in the neighborhood of the Madison Square Garden in central Manhattan, New York City, in March 2005. Hanna et al. (2004) reviewed the scientific goals for the project. MSG-05 was the first dispersion experiment in the Department of Homeland Security (DHS) Urban Dispersion Program (UDP).

The primary objective of the fouryear (20042007) New York City Urban Dispersion Program (UDP) (Allwine, 2004) is to enhance NYCs emergency capabilities for responding to potential airborne releases of harmful contaminants. This objective is to be accomplished: 1) by improving the permanent network of wind stations in and around NYC to better estimate where contaminants may travel, 2) by conducting field studies in NYC to advance knowledge about the movement of contaminants in and around NYC and into and within building interiors, 3) by improving and validating computer models that simulate the atmospheric movement of contaminants in urban areas using data collected from the field studies, and 4) by transferring the improved capabilities to NYC emergency agencies. This program is primarily sponsored by the U.S. Department of Homeland Security with additional support from the U.S. Department of Defense Defense Threat Reduction Agency, the U.S. Department of Energy, and the U.S. Environmental Protection Agency.

During each IOP, six different species of Perfluorocarbon Tracer (PFT) tracers were released from five different release locations. Two gasses were released from one site in order to have a measure of the repeatability of the tracer method. The dispersing plume was tracked with about 30 sampling stations at radial distances of about 0.2 and $0.4 \mathrm{~km}$ (Watson, 2005). The six PFTs were measured by batterypowered samplers attached to light poles at about threemeters above ground at each of 21 locations extending out to 400 meters from MSG. To determine the vertical extent of the tracer plume, ten portable tracer samplers were placed at five locations on surrounding buildings. Tracer samplers were located in Penn Station to give an indication of the infiltration of tracers into Penn Station, and tracer samples were collected using personal tracer samplers that were carried by individuals who walked in and around the MSG area and Penn Station.

This document provides details on the meteorological data that were collected during by Brookhaven National Laboratory (BNL) during MSG05. The meteorological data set is divided into three subsets with names given below,

1. MESO. A mesoscale array of meteorological stations. Both existing stations of acceptable quality and specially deployed stations were employed in the MSG05 mesonet data set. The mesonet instrumentation was deployed before the first IOP and operated for a considerable time after IOP2.

2. IOP1. The first Intensive Operation Period (IOP) was conducted on 20050310 from 08:00 to 14:00 Eastern Standard Time (see sectin 1.1 below). During each IOP, six special streetlevel meteorological stations and three setback stations were operated in the vicinity of MSG. Setback stations (Section 4.3) 
were located on two elevated locations on One Penn Plaza and on an awning at the Eigth Ave. entrance to the New York Hotel.

3. IOP2. The second IOP took place on 2005-03-14 from 08:00 to 14:00 in exactly the same manner as the first.

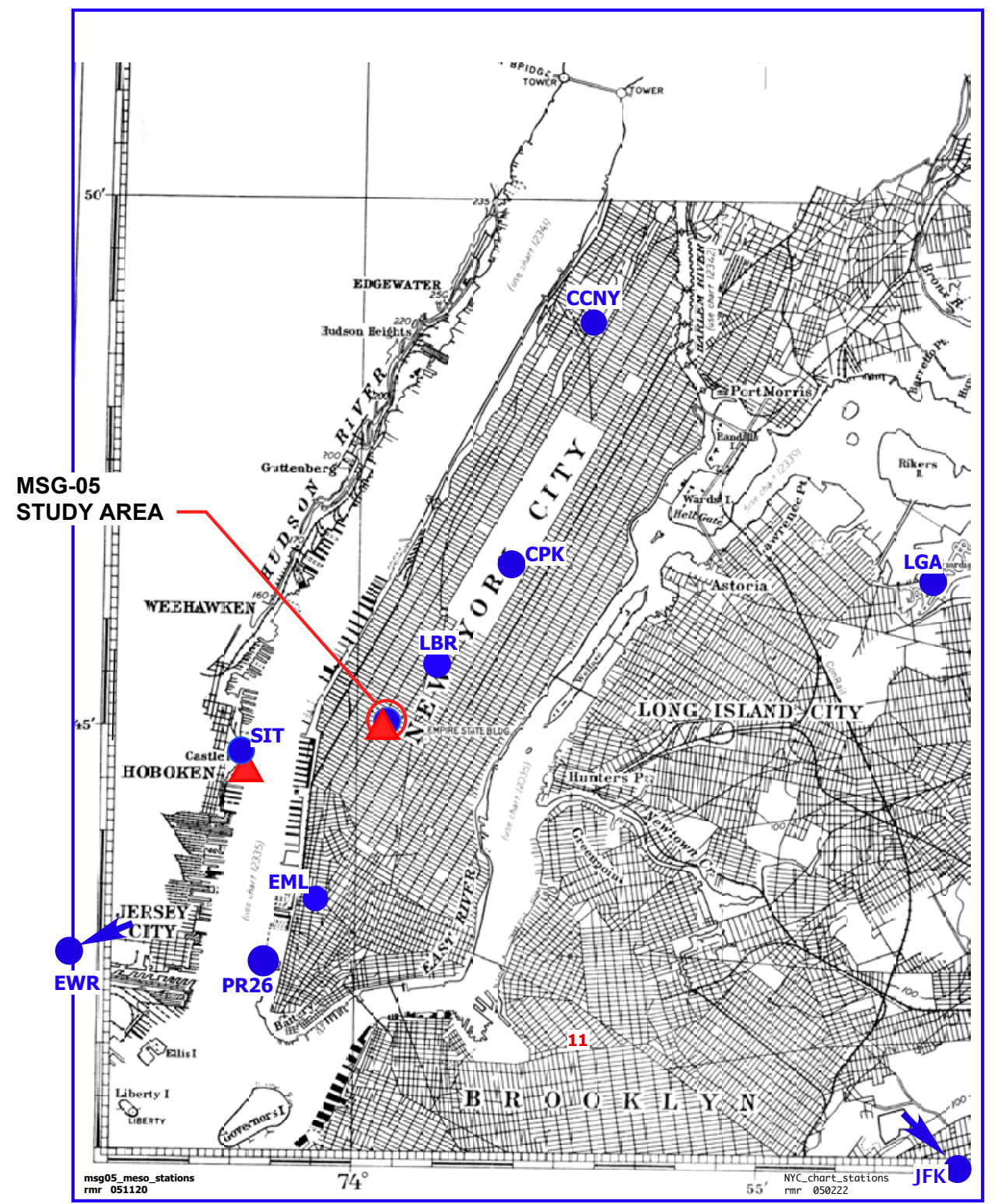

Figure 1: The mesonet stations used in the MSG-05 data set are shown on this marine chart. 


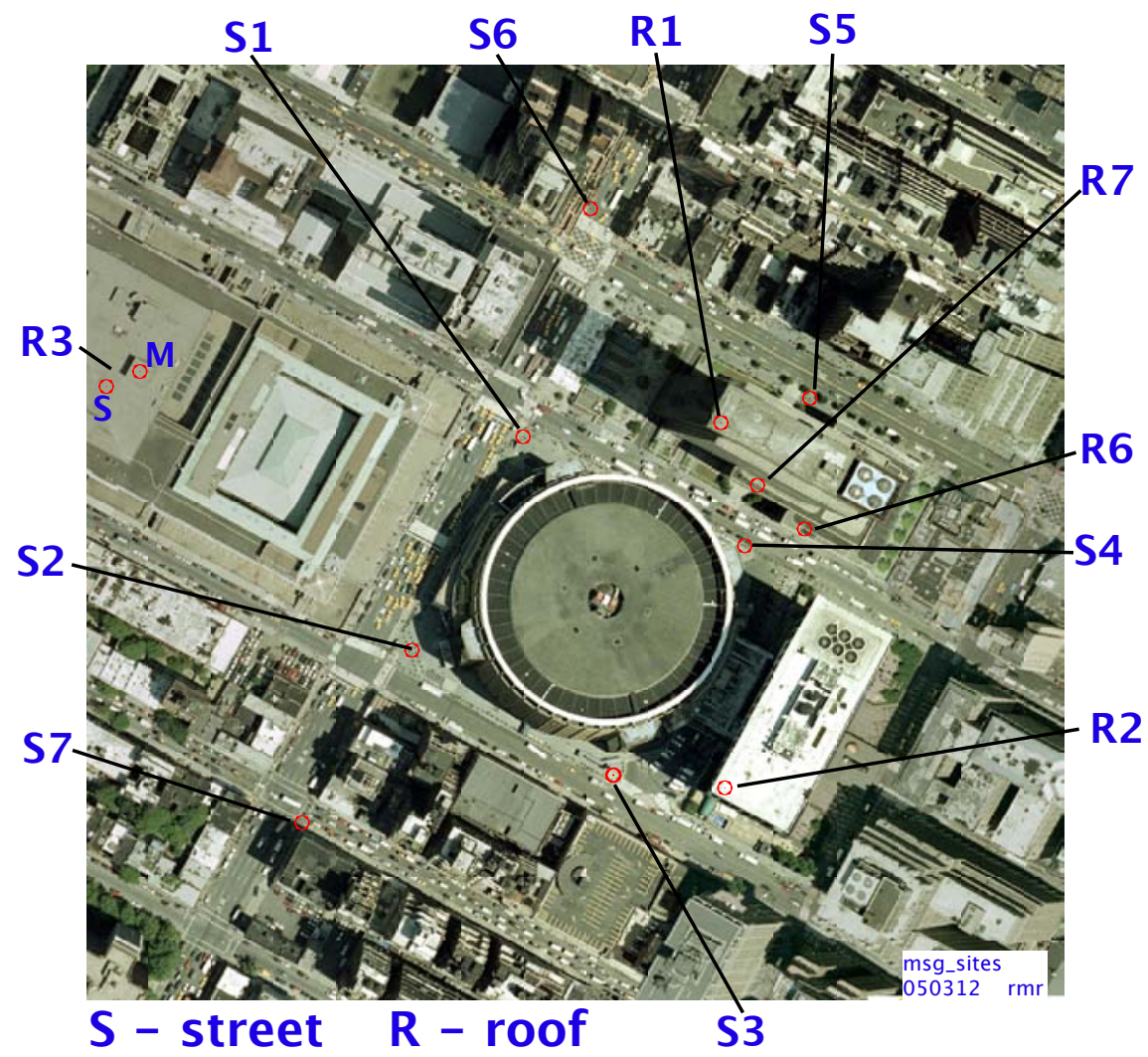

Figure 2: Locations of MSG-05 meteorological stations.

\subsection{Time Recording and Averaging}

In this data set, all dates and times are recorded and reported in Eastern Standard Time, unless otherwise specified. The EST time zone is -5 hours from Greenwich.

In general time is written from year to seconds left to right. For example a time of 20050310,072634 is equal to, in American format, 10 March 2005 7:26:34.

For all averaged data sets, the date/time mark represents the center of the averaging time. For instance, if an averaging interval is 300 seconds ( 5 minutes), the $0900 \mathrm{~h}$ average is derived from data samples from 085230 to 090230.

\subsection{Organization of this report}

This meteorological data report is organized along the same lines as the actual data archive file (see 2). Each observation station is described in Section 3 without regard to the data taken there. Similarly, the instrumentation is described in a general way in Section 4. Having described the locations and instruments, the different data sets are described in Section 6. There are three data sets in MSG-05: (1) MESO, the mesoscale network of rooftop installations and external data sets that we, more or less, continuously operating over the entire experiment period. (2) IOP1, the first tracer release exercise that occured on 10 March, and (3) IOP2, the second tracer release that occured on 14 March. Data collection and processing is described in Section 7 for each instrument system. The data quality assurance is reviewed in Section 8. The results are, as advertised, 
preliminary, and are presented here to provide some overview of the data set that can be used for further analysis by others.

\section{Data Organization}

The two goals of this technical report are to provide a complete description of the meteorological measurement sub-task to the MSG-05 experiment, and to provide a description of the data set that accompanies this report.

\subsection{Data processing levels}

We follow a common practice by segregating our data into three levels.

Level 0 Level 0 data are the raw data collected by whatever recording device is available. The raw $10 \mathrm{~Hz}$ data from the 3DSonic instrument are included here. Archive ASOS data downloaded from the NWS or other on line sources are collected here exactly as they came. In some cases raw level 0 data are cleaned to remove obviously bad records, spikes, and dropouts. As the original data are not altered, these files remain in the level 0

Level 1 The raw data becomes level 1when they are processed by applying calibration coefficients, wind direction rotations, and any corrections to produce data in true physical units.

Level 2 When the level 1 data are processed to produce "derived" variables or as different level 1 or level 2 data sets are combined, the data are classified as level 2. 


\subsection{Identification Codes}

In order to have a reasonable working environment, a set of ID codes has been developed in order to make unambiguous reference to any element of the project. A table of project ID codes is given below.

File and folder names that belong to a particular ID will begin with the ID followed by an underscore. For example, a folder might be named iop1_10MarchRelease and one knows that this folder contains level 1 or level 2 data from this IOP.

Table 1: A table of identification codes (ID) for different elements of the MSG-05 project. EXPERIMENT

msg | Overall experiment, MSG-05

DATA SEGMENTS

meso Continuous data over the experiment time period.

iop1 The first tracer release data set, 10 March 2005.

iop2 The second tracer release data set, 14 March 2005.

LOCATIONS

cony $\mathrm{CCNY}$ roof

cpk Central Park, Fort Belvedere

eml Environmental Measurements Laboratory, roof

ewr Newark Airport, ASOS site

fok Westhampton Airport, ASOS site

hpn White Plains Airport, ASOS site

hwv Shirley Airport, ASOS site

isp Islip Airport, ASOS site

jfk Kennedy Airport, ASOS site

Ibr Lehman Brothers roof site

lga LaGuardia Airport, ASOS site

p26 Pier 26, Hudson River site

r1 One Penn Plaza roof

r2 Two Penn Plaza roof

r3a Farley Post Office, utility roof

r3b Farley Post Office, maun roof (sodar)

r6 One Penn Plaza setback, 7th floor

r7 One Penn Plaza setback, 12th floor

s1 Street site, NW corner of MSG

s2 Street site, SW corner of MSG

s3 Street site, SE corner of MSG

s4 Street site, NE corner of MSG

s5 Street site, 34th Street in front of OPP

s6 NY Hotel overhang on 8th Ave.

s7 $\quad$ Street site, 8th Ave at 30th St, SE corner

sit Stevens Institute of Technology, Howe Center roof 
Table 2: A table of identification codes (ID) for different stations of the MSG-05 project. Notice that locations and stations are separate and distinct. In many cases, a location can have more than one station, for example the location sit, the roof of the Howe Center at Stevens Institute of Technology, has two stations, sit1, the meteorological station operated by the university, and sit2, the miniSodar operated as part of the MSG-05 experiment.

\begin{tabular}{l|l|c|l}
\multicolumn{2}{|c}{ STATION IDENTIFICATION CODES } \\
ID & DESCRIPTION & $\Delta T$ & MEDIA \\
ccny & NOAA GPS Met station & $1 \mathrm{~min}$ & html \\
cpk & Central Park, ASOS & $60 \mathrm{~min}$ & $\mathrm{ftp}$ \\
eml & DCNet station & $15 \mathrm{~min}$ & $\mathrm{ftp}$ \\
ewr & Newark Airport, ASOS site & $60 \mathrm{~min}$ & $\mathrm{ftp}$ \\
fok & Westhampton Airport, ASO & $60 \mathrm{~min}$ & $\mathrm{ftp}$ \\
hpn & White Plains Airport, ASOS & $60 \mathrm{~min}$ & ftp \\
hwv & Shirley Airport, ASOS & $60 \mathrm{~min}$ & ftp \\
isp & Islip Airport, ASOS & $60 \mathrm{~min}$ & ftp \\
jfk & Kennedy Airport, ASOS & $60 \mathrm{~min}$ & ftp \\
lbr & Lehman Brothers DCNet & $15 \mathrm{~min}$ & ftp \\
lga & LaGuardia Airport, ASOS & $60 \mathrm{~min}$ & ftp \\
p26 & SIT network, Pier 26, Hudson River & $5 \mathrm{~min}$ & html \\
r1 & One Penn Plaza, 10 Hz 3DSonic & $10 \mathrm{~Hz}$ & laptop \\
r2 & Two Penn Plaza, 10 Hz 3DSonic & $10 \mathrm{~Hz}$ & laptop \\
r3a & Farley Post Office, utility roof & $1 \mathrm{~min}$ & UHF coms \\
r3b & Farley Post Office, maun roof (sodar) & $1 \mathrm{~min}$ & laptop \\
r6 & OPP setback, 7th floor, 10 Hz 3DSonic & $10 \mathrm{~Hz}$ & laptop \\
r7 & OPP setback, 12th floor, 10 Hz 3DSonic & $10 \mathrm{~Hz}$ & laptop \\
s1a & Street site, 10 Hz 3DSonic & $10 \mathrm{~Hz}$ & laptop \\
s1b & Street site, WXT510 2DSonic & $3 \mathrm{sec}$ & laptop \\
s2 & Street site, 10 Hz 3DSonic & $10 \mathrm{~Hz}$ & laptop \\
s3 & Street site, 10 Hz 3DSonic & $10 \mathrm{~Hz}$ & laptop \\
s4a & Street site, 10 Hz 3DSonic & $10 \mathrm{~Hz}$ & laptop \\
s4b & Street site, WXT510 2DSonic & $3 \mathrm{sec}$ & laptop \\
s5 & Street site, 10 Hz 3DSonic & $10 \mathrm{~Hz}$ & laptop \\
s6 & NY Hotel, 10 Hz 3DSonic & $10 \mathrm{~Hz}$ & laptop \\
s7 & Street site, 10 Hz 3DSonic & $10 \mathrm{~Hz}$ & laptop \\
sit1 & SIT, Howe Center & $5 \mathrm{~min}$ & html \\
sit2 & SIT, Howe Center, sodar & $1 \mathrm{~min}$ & laptop \\
\hline & & &
\end{tabular}




\subsection{Directory Tree}

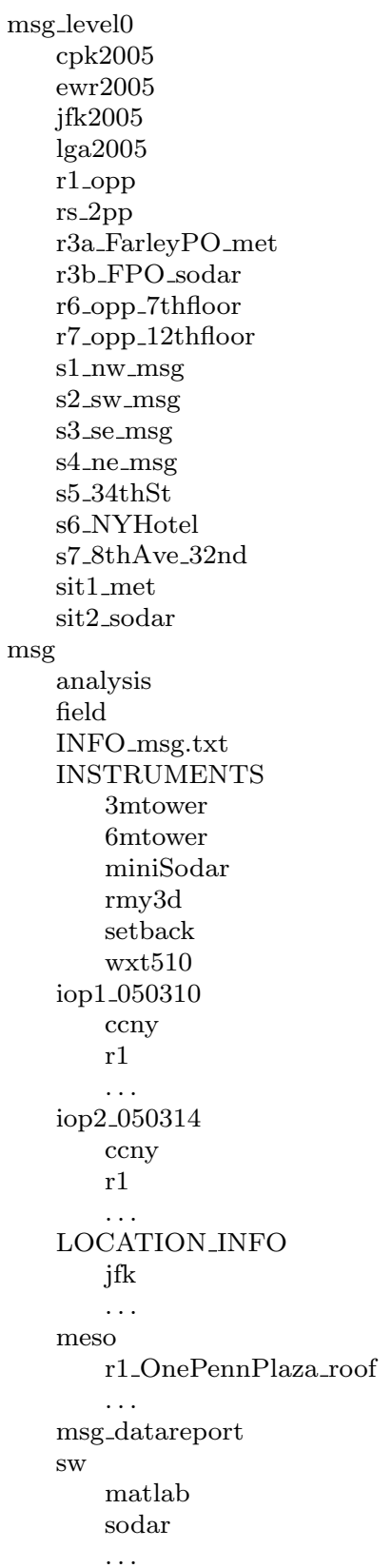

Table 3: level 0 folder organization.

All raw and cleaned raw data files are stored here.

ASOS station for Central Park for 2005

ASOS station for Newark airport for 2005

ASOS station for Kennedy airport for 2005

ASOS station for LaGuardia airport for 2005

Meso station on One Penn Plaza roof

Meso Station on Two Penn Plaza Roof

Meso station on the Farley Post Office roof

miniSodar on the FPO roof

3DSonic station on OPP 7th floor overhang

3DSonic station on OPP 12th floor overhang

ASOS station for JFK airport for 2005

ASOS station for JFK airport for 2005

ASOS station for JFK airport for 2005

ASOS station for JFK airport for 2005

ASOS station for JFK airport for 2005

ASOS station for JFK airport for 2005

ASOS station for JFK airport for 2005

ASOS station for JFK airport for 2005

ASOS station for JFK airport for 2005

Metadata, level 1 and level 2 time series, ...

All preliminary analysis results

data from the post-experiment field intercomparison

Information file for the MSG-05 experiment. (See below)

Descriptions of instruments and hardware

Describe the 3-m street station towers.

Describe the 6-m roof station towers.

Describe the AV miniSodar system.

Describe the R.M. Young 3DSonic and data collection system.

Describe the setback frame for wall deployments.

Describe the Vaisala WXT510 weather station with 2DSonic.

Results from the first IOP

A subset of the ccny meso data set.

A subset of the $\mathrm{r} 1$ meso data set.

Results from the second IOP

A subset of the ccny meso data set.

A subset of the $\mathrm{r} 1$ meso data set.

$\cdots$

Location metadata (See Table 1)

Location info for the JFK ASOS site. Photos, etc.

...

Results from the mesonet data set

Full level 1 data sets from OPP roof.

...

All images and source for this document

All data processing software for the MSG-05 project

matlab routines

PERL and Matlab routines for sodar processing 


\subsection{INFO Files}

We use simple text INFO files as the most reliable way of keeping track of metadata. All metadata INFO files are located with the particular data set in the archive. For instance if we want to know about the location with ID r1 we look at the INFO file msg/LOCATION_INFO/r1_*/INFO_r1.txt and find:

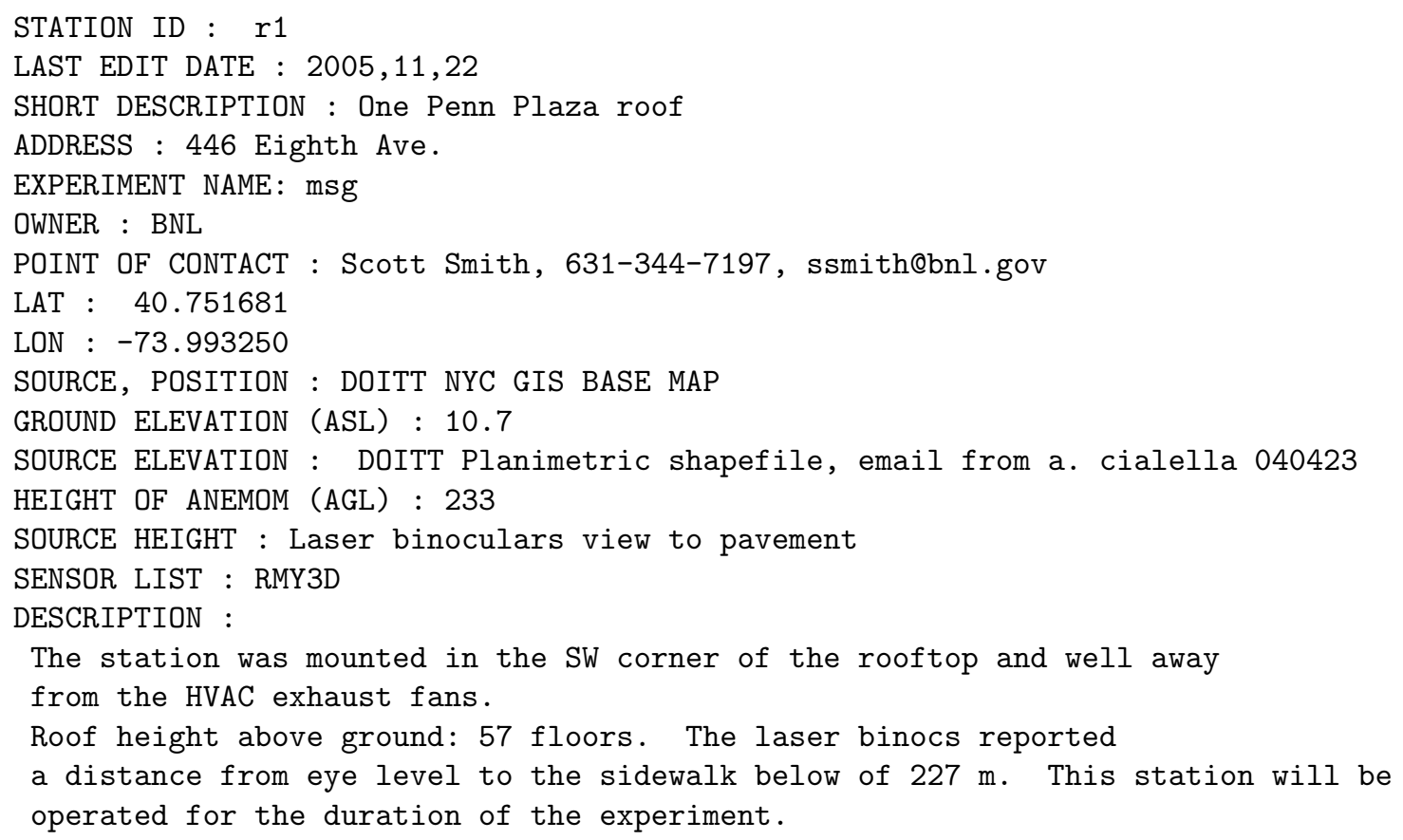

INFO files provide a convenient means of entering new information or editing data.

\section{Locations}

The MSG-05 data set has data from 27 different meteorological stations (Table 4). Each station was given a unique station identification code, the ID. Table 4 gives 
Table 4: Stations in the MSG-05 data set. ELEV is ground elevation above sea level in $\mathrm{m}$. HT is the height of the anemometer above ground in $\mathrm{m}$. The various instruments are described in Reynolds (2005).

\begin{tabular}{|c|c|c|c|c|c|c|}
\hline ID & TYPE & DESCRIPTION & LAT & $\mathrm{LON}$ & ELEV & HT \\
\hline ccny & NOAA & CCNY Roof, NOAA GPS station & 40.8167 & -73.950 & 58 & 58 \\
\hline cpk & ASOS & Central park, NOAA ASOS & 40.783 & -73.967 & 39.6 & 25 \\
\hline $\mathrm{eml}$ & DCNet & Environ Meas Lab, 15th floor, roof & 40.72842 & -74.006617 & 5 & 82 \\
\hline ewr & ASOS & Newark Airport ASOS & 40.717 & -74.167 & 2.3 & 10 \\
\hline fok & ASOS & Westhampton Gabreski Airport & 40.850 & -72.633 & 20.4 & 10 \\
\hline hpn & ASOS & White Plains Westchester Co Airport & 41.067 & -73.700 & 115.5 & 10 \\
\hline hwv & ASOS & Shirley Brookhaven Airport & 40.817 & -72.867 & 25 & 10 \\
\hline isp & ASOS & Islip Long Island Macarthur Airport & 40.800 & -73.100 & 25.6 & 10 \\
\hline jfk & ASOS & New York J F Kennedy Int'l Airport & 40.633 & -73.767 & 3.4 & 10 \\
\hline $\mathrm{lbr}$ & DCNet & Lehman Brothers roof & 40.76058 & -73.98301 & 16.8 & 160 \\
\hline $\operatorname{lga}$ & ASOS & New York Laguardia Airport & 40.783 & -73.883 & 3.4 & 10 \\
\hline $\mathrm{p} 26$ & MESO & Pier 26, Hudson River & 40.72122 & -74.01352 & 3 & 5.8 \\
\hline r1 & ROOF & One Penn Plaza roof & 40.75168 & -73.99325 & 10.7 & 233 \\
\hline r2 & ROOF & Two Penn Plaza roof & 40.74999 & -73.99219 & 8.8 & 133 \\
\hline r3a & $\mathrm{ROOF}$ & Farley P.O. met station & 40.75157 & -73.99632 & 10.4 & 34 \\
\hline $\mathrm{r} 3 \mathrm{~b}$ & SODAR & Farley Post Office (Sodar) & 40.75156 & -73.99632 & 10.4 & 24 \\
\hline r6 & SBACK & One Peen Plaza, 7th floor setback & 40.75073 & -73.99146 & 10.7 & 34 \\
\hline r7 & SBACK & One Penn, 12 th $\mathrm{fl}$ setback & 40.75080 & -73.99154 & 10.7 & 50 \\
\hline s1 & STREET & 33rd St., NW corner of MSG & 40.751283 & -73.993736 & 10.7 & 3 \\
\hline s2 & STREET & SW corner of MSG & 40.750377 & -73.994572 & 10.7 & 3 \\
\hline s3 & STREET & SE corner of MSG & 40.749727 & -73.993177 & 10.7 & 3 \\
\hline s4 & STREET & NE corner of MSG & 40.750775 & -73.992413 & 10.7 & 3 \\
\hline s5 & STREET & 34th St N of One Penn Plaza & 40.751497 & -73.992002 & 10 & 3 \\
\hline s6 & SBACK & NY Hotel Overhang, Eighth Ave. & 40.752472 & -73.993827 & 10.7 & 5 \\
\hline s7 & STREET & Street sta, SE corner 8th Ave and $30 \mathrm{t}$ & 40.749330 & -73.995447 & 10 & 3 \\
\hline sit1 & MESO & Stevens Inst. Tech, Howe Center & 40.74483 & -74.02385 & 32 & 51.8 \\
\hline sit2 & SODAR & Stevens Inst. Tech, Howe Center & 40.74483 & -74.02385 & 32 & 51.8 \\
\hline
\end{tabular}




\section{Instruments}

This section provides a review of the instrumentation used by BNL during the MSG-05 experiment. Other scientific groups provided additional instrumentation and these will be described in separate report.

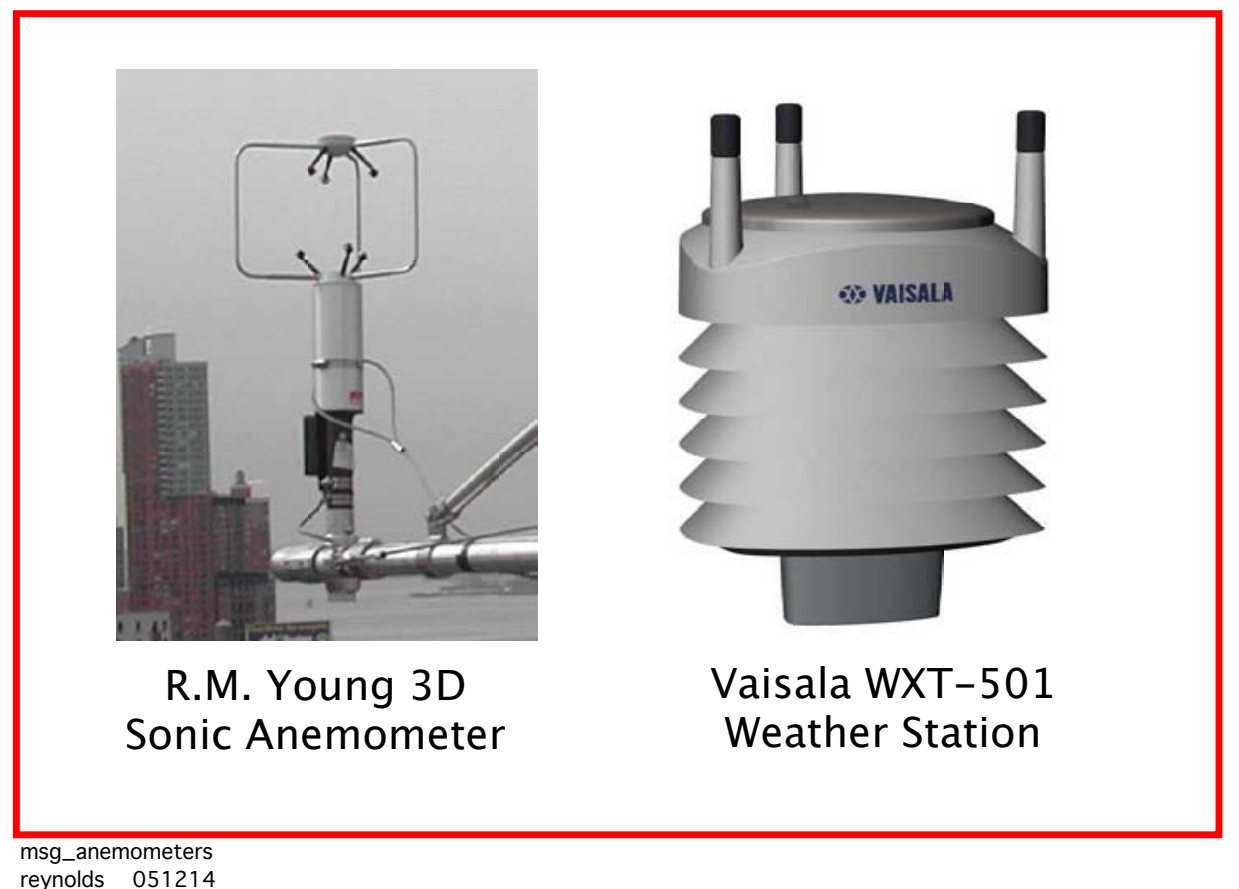

Figure 3: Anemometers used in the MSG-05 experiment. The R.M. Young model 81000 sonic anemometer measures the 3D wind vector at $10 \mathrm{~Hz}$. The WXT510 uses a 2D sonic anemometer and produces a mean horizontal wind vector each three seconds. This weather station also measures air temperature, relative humidity, barometeric pressure, and rainfall.

\subsection{Sonic anemometer}

The three-dimensional sonic anemometer (3Dsonic) was the model 81000 manufactured by R.M. Young Co. was used for turbulence measurements in this project (figure 3). The instrument brochure with all specification is given in Appendix A. Table 5, below, provides key characteristics for the measurements.

Table 5: Specifications and Settings for 3D sonic anemometers during MSG-05

$\begin{array}{llll}\text { Internal sampling rate } & 160 \mathrm{~Hz} & \text { Output sample rate } & 10 \mathrm{~Hz} \\ \text { Output format } & \text { ASCII } & \text { Output variables } & u, v, w, c, T_{\text {sonic }} \\ \text { wind speed range } & 0.01-40 \mathrm{~m} \mathrm{~s}^{-1} & \text { wind speed resolution } & \pm 0.01 \mathrm{~m} \mathrm{~s}^{-1} \\ \text { Valid wind elevation angles } & \pm 60^{\circ} & & \end{array}$

We note that sonic anemometers are well suited for urban locations, especially at street level, where wind speeds have considerable vertical flow and where wind velocities can be quite small. However, a limitation in this type of instrument is that measurements become suspect with the elevation from horizontal exceeds $\pm 60^{\circ}$. We will want to flag all 3Dsonic data where this limitation is exceeded.

The ASCII digital output from the 3Dsonic is collected by a laptop PC running a customized program called "ECCheck." ECCheck ingests each data line from the instrument and adds a time tag for the moment the 
record was received. It then writes a time stamped data record to a file. The data lines are position ordered as follows:

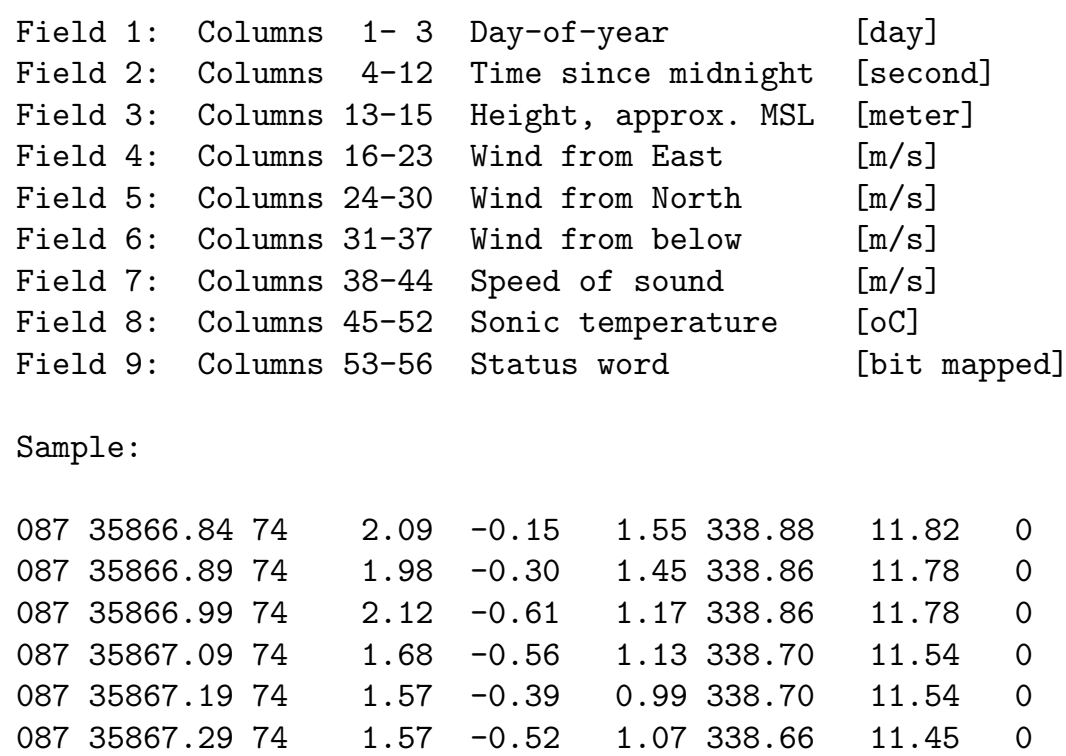

The output from an RMY 81000 sonic anemometer is not guaranteed to be space delimited. Field melding can occur, for example when tranducers get wet. (The status word will also be nonzero when this happens.) We use fixed column width for parsing the input raw data lines.

The wind vector is given by fields $4-6$ and is relative to the alignment of the sensor. Typically the sensor is aligned in an easy-to-use direction such as the edge of the a building roof or perpindicular to a street. Then the winds are converted to true North $(u, v, w)$ during processing.

Raw file names are written in the format

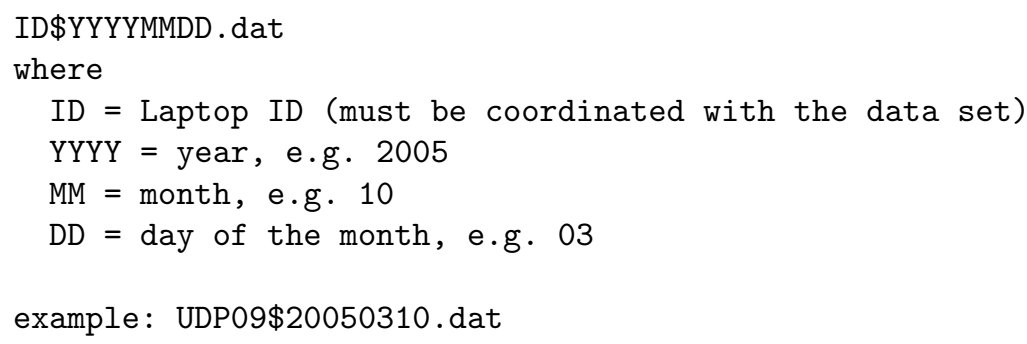

Date and time stamping are done by the data collection computer. Occasionally network delays and computer interrupts cause missed lines or a delay in the timestamp. These glitches are rare and easily removed during the data processing.

\subsection{Vaisala WXT510 weather station}

The Vaisala Weather Transmitter, WXT510, is a compact and lightweight multi-sensor instrument that measures the most essential weather parameters (Figure 3). It is a configurable product that can measure wind speed, direction, liquid precipitation, barometric pressure, temperature and relative humidity in one package. Appendix B provides an overall review of the WXT510, and specific settings for MSG-05 are given below.

The WXT510 connects to a laptop PC running an application called DataXbar. This program was developed at BNL for the express purpose of logging ASCII strings produced by digital instruments. DataXbar takes each 
Table 6: Specifications and Settings for Vaisala WXT510 weather transmitter.

$\begin{array}{llll}\text { Internal sampling rate } & ? ? \mathrm{~Hz} & \text { Output sample rate } & 3 \mathrm{sec} \\ \text { Output format } & \text { ASCII } & \text { Output variables } & S, D, T_{a}, R H, P, R_{i} \\ \text { wind speed } & 0.1-60 \pm 0.1 \mathrm{~m} \mathrm{~s}^{-1} & \text { wind direction } & \pm 1^{\circ}\end{array}$

record from the instrument as a string and prepends a date-time string before storing into memory. A data line from the WXT510, as setup for the experiment, is shown below:

2005-03-10, 08:03:59, OR0, $\mathrm{Dm}=116 \mathrm{D}, \mathrm{Sm}=4.5 \mathrm{M}, \mathrm{Ta}=-4.8 \mathrm{C}, \mathrm{Ua}=42.9 \mathrm{P}, \mathrm{Pa}=1008.5 \mathrm{H}, \mathrm{Ri}=0.0 \mathrm{M}$, $\mathrm{Th}=-2.3 \mathrm{C}, \mathrm{Vh}=10.8 \mathrm{~W}, \mathrm{Vs}=8.5 \mathrm{~V}, \mathrm{Vr}=3.529 \mathrm{~V}$

The line here longer than the page and has been shown in sections. The different fields in the raw line are as follows:

$\begin{array}{clc}2005-03-10 & \text { Instrument clock date (laptop) } & \\ 08: 03: 59 & \text { Instrument time (laptop) } & \\ \mathrm{DM}=116 \mathrm{D} & \text { Vector mean wind direction } & \mathrm{deg} \\ \mathrm{Sm}=4.5 \mathrm{M} & \text { Vector mean speed } & \mathrm{m} \mathrm{s}^{-1} \\ \mathrm{Ta}=-4.8 \mathrm{C} & \text { Air temperature } & { }^{\circ} \mathrm{C} \\ \mathrm{Ua}=42.9 \mathrm{P} & \text { Relative humidity } & \% \mathrm{RH} \\ \mathrm{Pa}=1008.5 \mathrm{H} & \text { Barometric pressure } & \mathrm{hPa} \\ \mathrm{Ri}=0.0 \mathrm{M} & \text { Rain intensity } & \mathrm{mm} / \mathrm{hr} \\ \mathrm{Th}=-2.3 \mathrm{C} & \text { Heater temperature } & { }^{\circ} \mathrm{C} \\ \mathrm{Vh}=10.8 \mathrm{~W} & \text { Heater voltage } & \text { volts } \\ \mathrm{Vs}=8.5 \mathrm{~V} & \text { Input voltage } & \text { volts } \\ \mathrm{Vr}=3.529 \mathrm{~V} & \text { Reference voltage } & \text { volts }\end{array}$

The date and time here are produced by the data acquisition computer and are prepended by DataXbar program.

\subsection{Tripod towers and setback frames}

Two types of tripod towers were used in MSG-05 (figure 4). Rooftop deployments used a 6-m tower made from schedule 40 aluminum pipe and coupler fittings. The design allows for rapid installation yet can withstand winds greater than $60 \mathrm{~m} \mathrm{~s}^{-1}$.

The same design was modified to produce 3-m tripod towers for the street stations.

\section{4 miniSodar}

Sodar (sonic detection and ranging) systems are used to remotely measure the vertical turbulence structure and the wind profile of the lower layer of the atmosphere. Sodar systems are like radar (radio detection and ranging) systems except that sound waves rather than radio waves are used for detection. Other names used for sodar systems include sounder, echosounder and acoustic radar. A more familiar related term may be sonar, which stands for sound navigation ranging. Sonar systems detect the presence and location of objects submerged in water (e.g., submarines) by means of sonic waves reflected back to the source. Sodar systems are similar, except the medium is air instead of water, and reflection is due to the scattering of sound by atmospheric turbulence.

Sodars operate on the principle of acoustic backscattering. An electronic sound driver is used to generate an acoustic pulse into the atmosphere with a frequency typically between 1 and $5 \mathrm{KHz}$. The duration of each pulse is usually between 50 and $300 \mathrm{~ms}$. As the sound wave propagates through the atmosphere, a small fraction of its energy is scattered back to the surface by small scale temperature inhomogeneities whose scale is similar to that of the wavelength of the acoustic pulse (Gaynor, 1977). The backscattered signal is amplified and the received time series is subdivided into time blocks, called range gates, each representing a discrete layer in the 
atmosphere. Any number of algorithms are employed to determine the mean frequency of the backscattered signal (Neff and Coulter, 1986).

The Doppler shift, that is to say the difference between the transmitted frequency and the backscattered frequency, is directly proportional to the radial wind velocity along the acoustic beam axis. Determination of the total wind vector requires a minimum of three independent radial wind velocities. The miniSodar uses three narrow beams, one vertical and two at an angle of, typically, $6^{\circ}$ from vertical. Computation of the three dimensional wind vector at the range gate height relies on an assumption that the wind field is horizontally homogenious, or varies in space very gradually since the radial wind vectors are separated in space. (At $h=100 \mathrm{~m}$, the separation will be $20 \mathrm{~m}$ ).

Sodars which use acoustic frequencies less than $2 \mathrm{KHz}$ generally have a maximum sounding range of 1 to $2 \mathrm{~km}$ (Clifford et al., 1994). The range of a sodar using acoustic pulses greater than $2 \mathrm{KHz}$ drops off dramatically with increasing frequency because of the effects of molecular attenuation. A sodar with a transmit frequency of 4 to $5 \mathrm{KHz}$ has a maximum range of about 200 to $300 \mathrm{~m}$ in quiet environments. Urban environments are notoriously noisy and limit the usefulness of sodars. However, most environmental noise tends to exhibit frequencies less than $2 \mathrm{KHz}$ and its spectrum falls off sharply as frequency increases. The challenge is attempting to find a balance which will maximize sodar range and minimize noise interference.

Sodars for atmospheric research were first developed in Australia in the late 1960's (McAllister et al. (1968); Little (1969); Beran (1970); Reynolds (1970)). The sodar became a commercial product in 1978 Schwieson (1986). The miniSODAR, the instrument used in this study, was developed by AeroVironment Inc. in the late 1980's to measure wind profiles in helicopter landing areas where noise levels were extreme. It was made commercially available in 1994 and has been deployed in situations where winds within the lowest $200 \mathrm{~m}$ are needed and ambient noise in the lower frequency range $(1000-2000 \mathrm{~Hz})$ is high. It was determined that the optimum frequencies to operate SODAR in these conditions was near $4500 \mathrm{~Hz}$. The same conclusion was reached by Crescenti and Baxter (1998) and Crescenti (1998) for the urban environment where automobiles and HVAC systems can add considerable ambient noise.

The following table lists the specifications for the miniSodar.

Table 7: Settings for miniSodars used during MSG-05

$\begin{array}{llll}\text { Maximum Sampling Altitude } & 200 \mathrm{~m} & \text { Power input (electrical) } & 30 \mathrm{~W} \\ \text { Minimum sampling Altitude } & 15 \mathrm{~m} & \text { Power output (acoustic avg) } & 40 \mathrm{~W} \\ \text { Height Resolution } & 10 \mathrm{~m} & \text { Voltage } & 120 / 220 \mathrm{VAC} \\ \text { Transmit frequency } & 4500 \mathrm{~Hz} & \text { Weight } & 255 \mathrm{lbs} \\ \text { Averaging interval } & 60 \mathrm{~min} & \text { Antenna ht } & 1.2 \mathrm{~m} \\ \text { Wind speed range } & 0-35 \mathrm{~m} \mathrm{~s}^{-1} & \text { Antenna Width } & 1.2 \mathrm{~m} \\ \text { Wind speed accuracy } & <0.5 \mathrm{~m} \mathrm{~s}^{-1} & \text { Antenna length } & 1.5 \mathrm{~m} \\ \text { Wind direction accuracy } & <5^{\circ} & \text { Total ht with collar } & 2.1 \mathrm{~m} \\ \text { Beam width } & ?^{\circ} & \text { Beam zenith angles } & 6^{\circ}\end{array}$




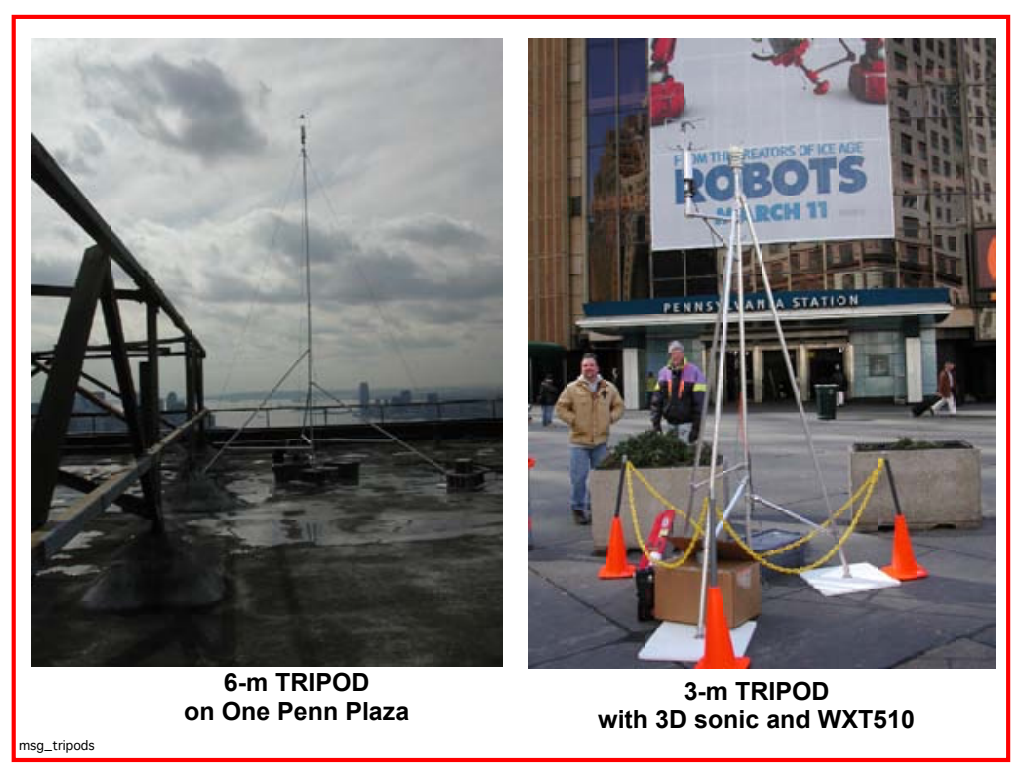

Figure 4: Tripods used in the MSG-05 experiment. The 6-m tripod is free standing and capable of withstanding $60 \mathrm{~m} / \mathrm{s}$ winds. The 3-m tripod shown here supports both the 3Dsonic anemometer and the WXT510 weather transmitter.

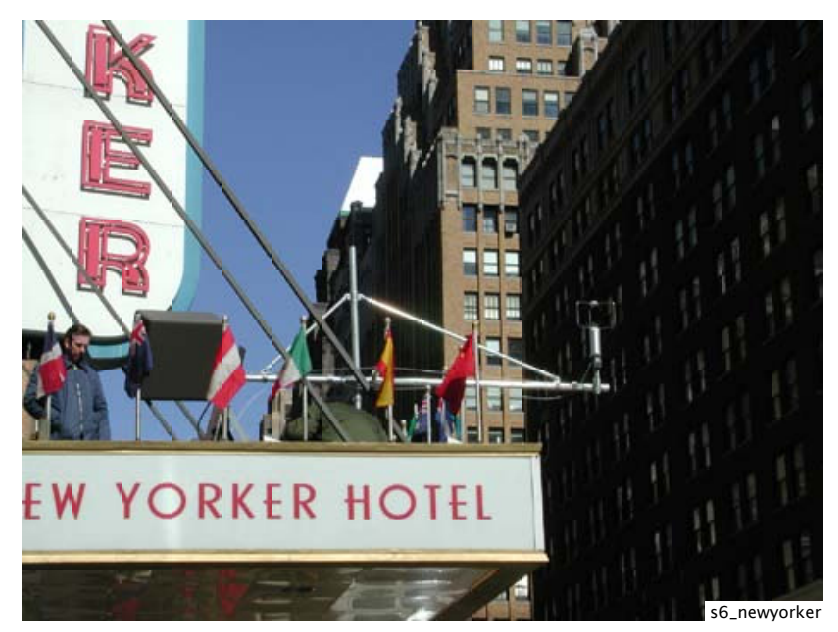

Figure 5: The setback station S6 on the New Yorker Hotel Overhang. 


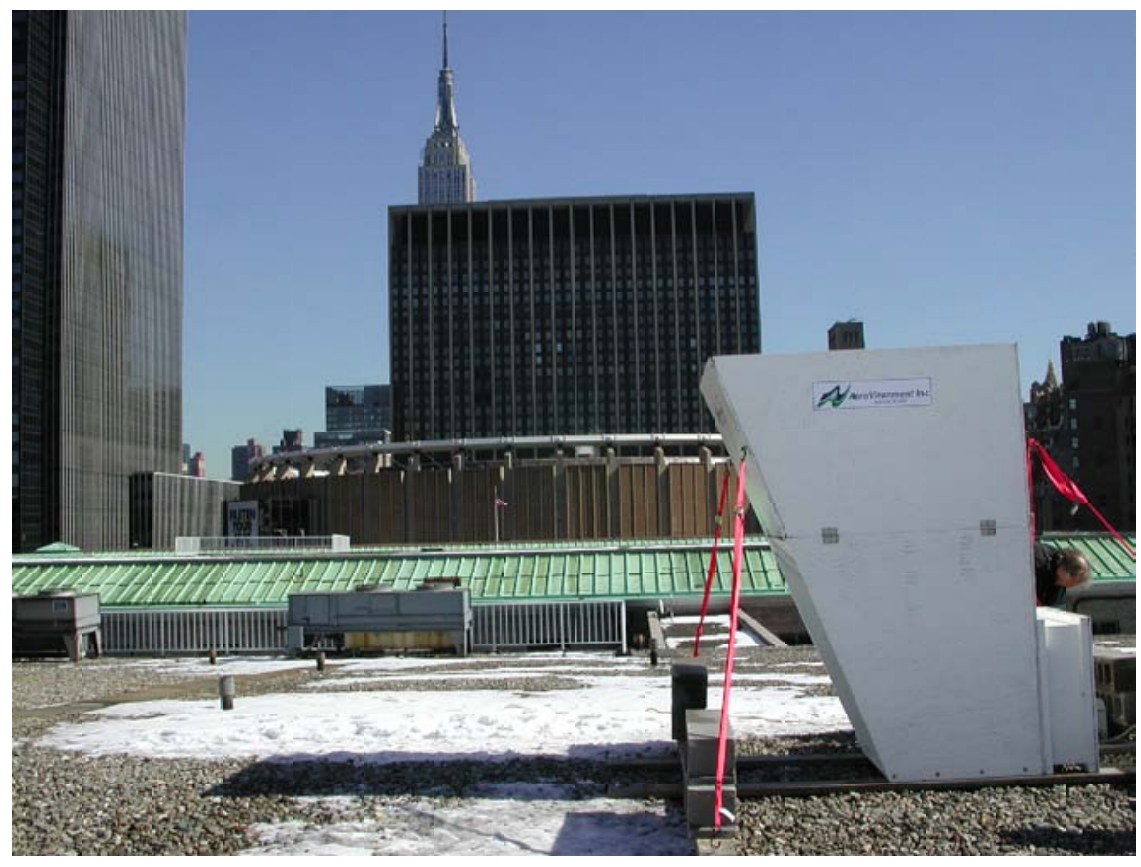

Figure 6: A miniSodar on the Farley Post Office roof during the MSG-05 experiment. In the background, from left to right, are One Penn Plaza, Madison Square Garden, and Two Penn Plaza. 


\subsection{External Instrumentation}

\subsubsection{CCNY}

The NOAA-CREST weather station, located on the roof of the Science Building, began operation on 12 December, 2003. The station's sensors collect data each second and compute one-minute averages. The information is relayed to the Engineering building via the campus internet. Archived data is available on the NOAA-CREST web site. Data includes wind speed, direction and their vectors; air, dew point, wet bulb, heat index and wind chill temperatures; relative humidity; air pressure; rain; plant trans-evaporation and solar flux. More information on this site can be found at http://icerd. engr. ccny. cuny. edu/noaa/wc/.

\subsubsection{NOAA ASOS}

The Automated Surface Observing Systems (ASOS) program is a joint effort of the National Weather Service (NWS), the Federal Aviation Administration (FAA), and the Department of Defense (DOD). The ASOS systems serves as the nation's primary surface weather observing network. ASOS is designed to support weather forecast activities and aviation operations and, at the same time, support the needs of the meteorological, hydrological, and climatological research communities.

Reports basic weather elements:

- Sky condition: cloud height and amount (clear, scattered, broken, overcast) up to 12,000 feet

- Visibility: (to at least 10 statute miles)

- Basic present weather information: type and intensity for rain, snow, and freezing rain

- Obstructions to vision: fog, haze

- Pressure: sea-level pressure, altimeter setting

- Ambient temperature, dew point temperature

- Wind direction, speed and character (gusts, squalls)

- Precipitation accumulation

- Selected significant remarks including- variable cloud height, variable visibility, precipitation beginning/ending times, rapid pressure changes, pressure change tendency, wind shift, peak wind.

More information on this site can be found at http://www.nws.noaa.gov/asos/.

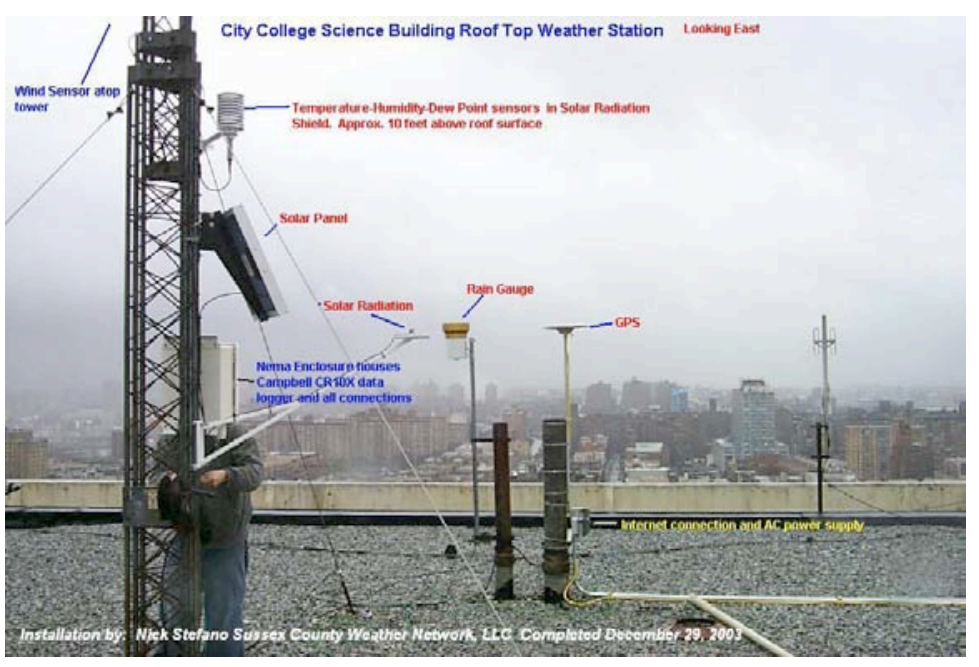

Figure 7: The CCNY weather station, east view.

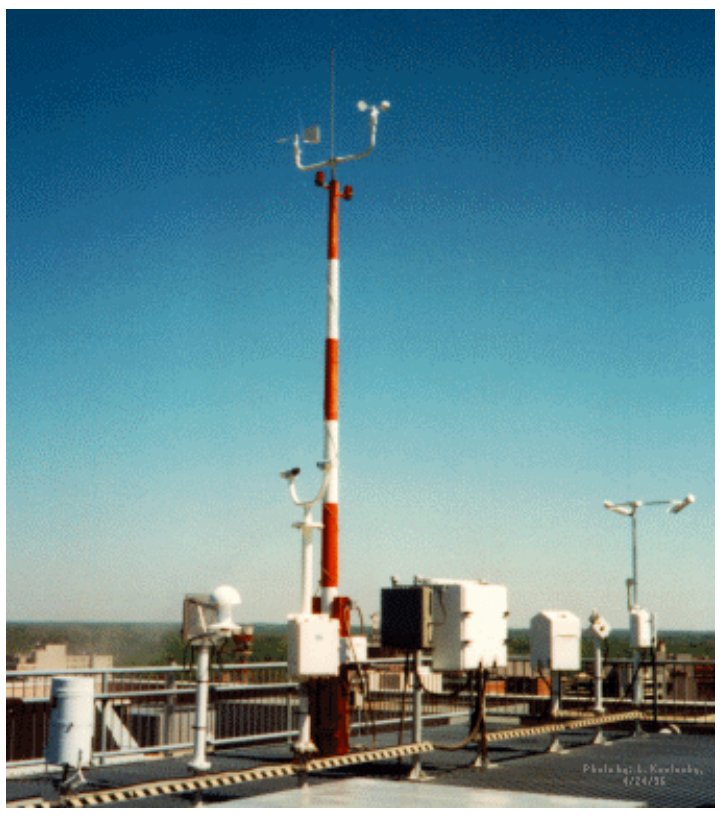

Figure 8: A typical ASOS weather station

\subsubsection{NOAA DCNet}

\subsubsection{Stevens Institute of Technology}

The New York Harbor Observing and Prediction System (NYHOPS) was established to permit an assessment of ocean, weather, environmental, and vessel traffic conditions throughout the New York Harbor region. The system is designed to provide a knowledge of meteorological and oceanographic conditions both in real-time and forecasted out to 48 hours in the Hudson River, the East River, NY/NJ Estuary, Raritan Bay, Long 
Island Sound and the coastal waters of New Jersey. In this web site you will see graphic images of water level, surface and bottom temperature, surface and bottom salinity, surface and bottom currents and NOAA meteorological predictions. Real time data is only available in the NY/NJ Estuary. For more information see http://hudson.dl.stevens-tech.edu/NYHOPS/

\section{$5 \quad$ MSG Deployment Procedures}

Two main issues are involved in each deployment. (1) The tripods must be vertical to $< \pm 0.5^{\circ}$, and (2) The anemometers must be aligned in a known direction so that measurements can be reduced to a true north alignment.

\subsection{Roof wind station deployment}

The alignment is towards the northward roof edge. By northward edge we mean that a perpindicular line from the station to the roof edge lies in an approximate northerly direction. This alignment is easy to do during the installation. The orientation of the roof edge can be found to good accuracy using GIS or survey data.

\subsection{Setback station deployment}

The lubber line of the instrument faces perpindicular to the face of the setback so that relative $(u, v, w)$ are aligned up the street to the right, away from the building face, and upwards. Thus, $\pm u$ is flow up or down the street, $\pm v$ is flow away from or into the face of the building. As above, when we know the orientation of the building face we can transform the measurements to a true north coordinate system.

\subsection{Street wind station deployment}

Street stations are aligned either perpindicular to the street or along the Avenues. The true north orientation is computed during data processing.

\subsection{Sodar Installation and Operation}

The miniSodar has a North reference direction (the "lubber line" in nautical terms) and this defines the computed wind vector, $(u, v, w)$ in vector wind convention, the direction toward which the wind is blowing. In an urban environment on a rooftop, it is difficult to determine the exact direction of true North. Instead we align the sodar to be perpendicular to the northern roof edge. The exact alignment of the building, and thus its northern roof edge, can be determined from GIS data bases or from known building surveys. The sodar alignment is recorded and the wind direction is corrected during the data processing. 


\section{Data Processing}

\subsection{WXT510 Weather Station Processing}

The WXT provides spd, dir, ta, rh, p, and rain each 3 seconds.

Each 3sec record is saved as a raw file.

Each 3s spd/dir pair are converted to u/v (no coord xform).

Each dir is converted to unit vector components $\mathrm{x} / \mathrm{y}$.

$\mathrm{u}, \mathrm{v}, \mathrm{x}, \mathrm{y}, \mathrm{ta}, \mathrm{rh}, \mathrm{p}$ are summed over the avg interval (5 or $10 \mathrm{~min}$ ).

Also the squares are summed for stdev calculations.

Averages U, V, X, Y, TA, RH, P are computed.

Stdev's of all are computed from sums and sums of squares.

$\mathrm{U} / \mathrm{V}$ are rotated to the true $\mathrm{N}$ frame of reference.

S/D are computed from U/V.

$\mathrm{X} / \mathrm{Y}$ are used to compute sigmatheta via Yamartino.

\section{4 miniSodar Data Processing}

The miniSodar software is called "SodarPRO" a two(??) different versions were used during the 15month experiment. SodarPRO parameter set were as follows:

The AV system produces an ascii raw data file each time step (1 minute). The files contains a matrix of range heights versus computed variables for that range. The following variables are extracted verbatim from the raw AV data file:

yyyy MM dd hh mm ss d_sec z wspd wdir Av_u sig_u snr_u

Av_v sig_v snr_v Av_w sig_w snr_w

where $\mathrm{z}$ is the measurement height and represents the center of the range gate in meters; [Av_u sig_u snr_u] are the average $\mathrm{X}$ wind speed over the averaging perod, the standard deviation of the $\mathrm{U}$ (East) wind vector, and the mean signaltonoise ration during the averaging time. The same applies to the $\mathrm{V}$ (North) vector and the $\mathrm{W}$ (up) vector. 
The sample time (yyyy $M M d d h h \mathrm{~mm} \mathrm{ss}$ ) is the time at the end of the averaging period and is the time reported in the AV raw file with no correction for time zone.

The AeroVoronment SODAR program, "SodarPRO," processes incoming acoustic data and produces raw data files. At the end of each averaging period, one minute for the NYC experiment, a data block is written to an ascii raw data file. An example of one data block is given in Appendix C. When the signal-to-noise ration, "snr", falls too low, i.e. the measurements are given a missing value of 99.99 for floating point numbers and 9999 for integers. The wind components, $(u, v, w)$, along with the standard deviation and the average snr for each component are listed. The components are combined to compute an average wind speed and direction for the one minute averaging period.

However, SodarPRO only tags the worst of the data. Non-missing raw data from any height interval is still repleat with noise problems and it is the challenge of the post-processing software to find and remove the sporadic noise contamination. Post processing software is aimed at producing the best possible time series of horizontal and vertical winds for any given height. Data is thus separated

Program read_sodar_dat.pl reads the ascii data file from the AV program and extracts a specific height range gate. Extraction is verbatim, e.g. no corrections are made to the raw AV output data. Specific range gate heights

\section{Detecting and Correcting Sodar Errors}

Techniques for removal of sporadic errors have been provided by Fleming (Fleming and Hill, 1982) and Taylor(Taylor, 1982). The Chauvenet's Criterion method was used to reject outlying points. In each averaging interval a set of scalar measurements can be represented by $x=\left(x_{0}, x_{1}, x_{2}, \ldots x_{n-1}\right)$. The mean, $\bar{x}$ and standard deviation, $\sigma_{x}$ are computed. The maximum value is used to compute the relative size of the maximum outlier: $\left.t=\left(x_{\max }-\bar{x}\right) / \sigma_{x}\right)$ and this is used in the error function to estimate the probability of a single point being this far away from the mean.

$$
P(x>=t)=\operatorname{erfc}(t / \sqrt{2})=\frac{2}{\sqrt{\pi}} \int_{x}^{\infty} e^{-t^{2} / 2} d t
$$

If, for $n$ points, the product $n P(x>=t)<=0.5$, the datum is rejected. If a point is rejected, the process is repeated at least one more time.

Noise in the SODAR data occurs often as sporadic bursts which are effectively removed by the Chauvenet's criterion, described above. Occasionally an averaging time block will be primarily "bad" data and in this case chauvenet's criterion fails to work properly because it will remove the good data points which are in a minority. An ad hoc method was developed from trial and error. When an averaged block is dominated by noise, the resulting value of $S_{v}$, the vector mean speed tends to jump significantly from surrounding good data. An example time series might be $S_{v}=\{\ldots, 1.45,1.96,2.21,22.34,15.55,1.45,1.98, \ldots\}$.

The final cleaning process compares the current value of $S_{v}$ with the previous value. If the time gap since the last good block is less than 2 hours and if the difference between $S_{v}$ (now) $-S_{v}$ (last) $<10 \mathrm{~m} \mathrm{~s}^{-1}$, then the block is recorded, otherwise it is rejected. This last procedure removes almost all of the sporadic periods of noise.

Table 8: Results from the three-step cleaning process for SODAR wind time series from different levels above the roof. The SODAR deployment period was 471.4 days and during this time the data recovery was $94.1 \%$. Outtages were due to software crashes and a power failure. Of the recovered data, the number of bad winds, $N_{\text {error }}$, varied from $3 \%$ at $20 \mathrm{~m}$ to $18 \%$ data loss at $60 \mathrm{~m}$.

\begin{tabular}{cccc}
$Z$ & $N$ & $N_{\text {error }}$ & $\%$ bad \\
\hline 20 & 42596 & 1105 & 3 \\
40 & 42596 & 3817 & 9 \\
60 & 42596 & 7767 & 18 \\
\hline
\end{tabular}


Double checking and reality checks.

Becuase of the considerable difference between the wind roses from the anemometer and the sodar (Fig. ??) the programs and the output files were double checked in a step-by-step fashion. This was done during the initial development of the code, but was repeated with great care as a caution. After verifying the software, comparison plots of sodar and anemometer data were made for short time blocks throughout the time series.

The Comparison Wind Station The NOAA Air Resources Laboratory (ARL) deployed a meteorological station on the EML building in February 2003 as a permanent installation. 


\section{Quality Assurance and Data Uncertainty}

Precaution and cross-checking have been practiced to assure that the data are of good quality. The following specific steps have been followed:

1. All instrumentations was factory calibrated before the experiment. During the deployments, all instrumentation serial numbers are recorded and we make sure each instrument at each station is exactly the same for each IOP.

2. Two street stations had dual instrumentation, a 3DSonic anemometer and a Vaisala WXT510 2Dsonic weather station. Data from these two instruments, involviing independent data collection and data processing, compare very well. The comparison is discussed below.

3. After the experiment, all instruments were taken to the BNL meteorological field and operated together for an extended time. This intercomparison had excellent results and further confiemed the veracity of the experiment measurements. (Also discussed below.)

4. Model validation. The experiment measurements agree well with the various CFD model results. Of course the idea of the measurements is to validate the models and so it is disingenuous to reverse the comparison. Nevertheless, approximate agreement suggests there were no gross errors such as might occur if the wind direction conventions (blowing from or to) are wrong.

5. We rely on a process of user feedback followed by a new release of data. Errors, typos, or processing errors in the archive data set are noted and on a routine basis a new release of the data will be made. This document will carry a summary sheet which outlines all changes in the data set for each release.

\subsection{D sonic and WXT comparisons at two street stations}

Two street stations, S1 and S4, were configured with two different types of wind instruments. The RMY 3D sonic anemometer and the new WXT510 2D sonic digital weather station were operated side-by-side as shown in Figure 4. Each of these instruments was aligned to relative north independently from the other. This was considered a good opportunity to evaluate the performance of the new WXT instruments against the widely used RMY 3dsonic anemometers.

The horizontal winds measured by the 3D sonic anemometer and the WXT weather station are compared in Figures 9 and 10. All data shown here come from the $300 \mathrm{sec}$ vector averaged wind time series. The 3dsonic sampled at $10 \mathrm{~Hz}$ so 3000 points were averaged. The WXT510 sampled at about $6 \mathrm{~Hz}$ but produced averaged output lines each $3 \mathrm{sec}$ (This is the minimal record interval possible for the WXT.) so only about 100 points were included in the 300 -sec average.

A group of four graphs are show here for each IOP and for each dual station. The upper left panels in each group shows the inverse relationship between $\sigma_{\theta}$ and windspeed $v$. However, the mean difference and standard deviation in the difference $\left(\sigma_{\theta R}-\sigma_{\theta W}\right)$ are only $2.3^{\circ}$ and $2.1^{\circ}$ respectively.

The upper right panel compares the variability in the wind direction difference, $\theta_{R}-\theta_{W}$, as a function of wind speed. When $v<0.5 \mathrm{~m} \mathrm{~s}^{-1}$, the differences become quite large. This might be expected. Note that the wind vectors we consider here are vector averages and it is possible to have a very small mean wind speed in a strongly turbulent situation.

The lower left panel is a histogram of the vector mean wind speed difference and the lower right panel shows a histogram of the direction differences. Because the direction difference is so noisy at low wind speeds, we show data here only when $V>0.5 \mathrm{~m} \mathrm{~s}^{-1}$. The comparisons for the two stations in the two IOPs are as follows 


\begin{tabular}{c|c|c||c|c|} 
& \multicolumn{2}{|c}{ IOP1 } & \multicolumn{2}{c}{ IOP2 } \\
& $\mathrm{S} 1$ & $\mathrm{~S} 2$ & $\mathrm{~S} 1$ & $\mathrm{~S} 2$ \\
\hline$\Delta v$ & -0.03 & -0.01 & 0.03 & -0.18 \\
$\sigma_{\Delta v}$ & 0.08 & 0.07 & 0.05 & 0.11 \\
\hline$\Delta D$ & 0.22 & -3.64 & 2.01 & 0.60 \\
$\sigma_{\Delta D}$ & 1.31 & 3.85 & 0.91 & 1.08
\end{tabular}



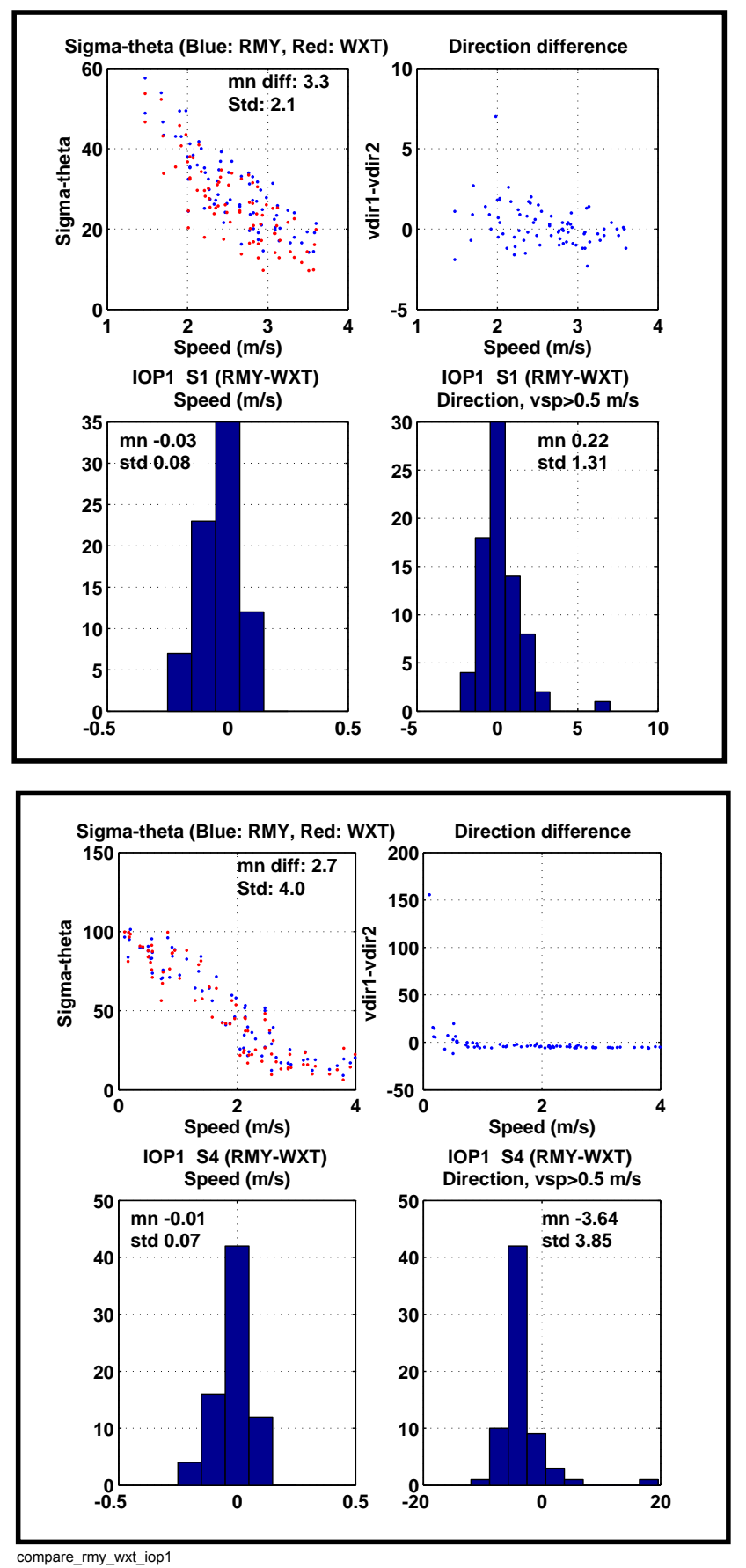

Figure 9: Comparison of winds measured by RMY3d and WXT510 during IOP1. 

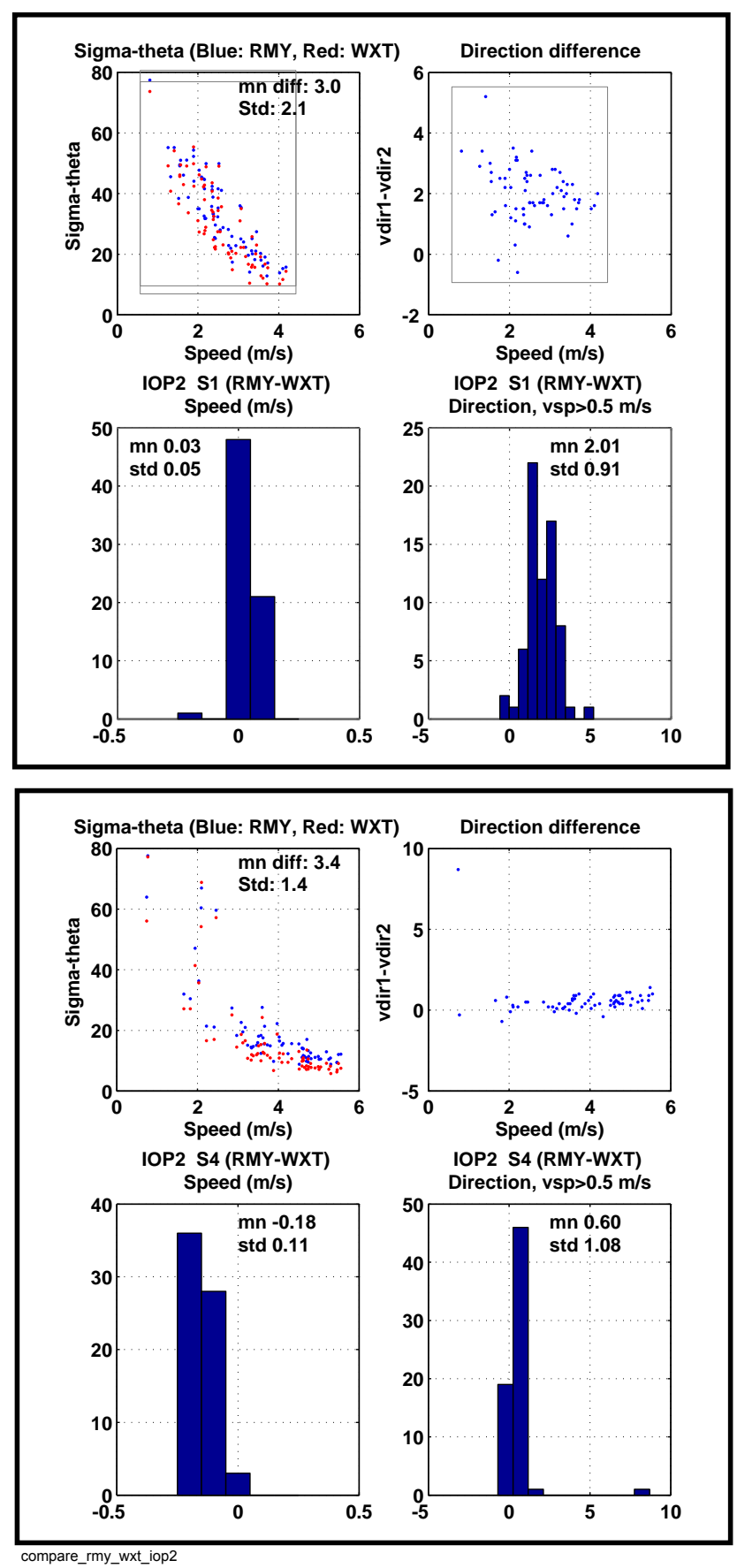

Figure 10: Compare RMY3d and WXT510 during IOP2. 


\subsection{Post Experiment Field Intercomparisons}

After the experiment, all instrumentation was brought to the BNL meteorological field for a field intercomparison. Stations S1, S2, S3, S4, S5, and S7 were intercompared by setting them up in the same location in the middle of the large open (approx 4 hectare) field where the BNL meteorological tower is located. The tripods were spaced about $10 \mathrm{~m}$ apart in a N-S alignment. In this way we could have good exposure as long as the wind was not in the sectors of $340-20^{\circ}$ and $160-200^{\circ}$. The instruments were operated for three days. The vector mean wind speed and directions are shown in Figure 11.

From the beginning of the intercomparison to about $16 \mathrm{hr}$ on the next day winds were consistent, strong, and from about $300^{\circ}$. After that a period of very low, irratic, and northerly winds ensued. The latter period was not used for the intercomparison because sheltering of the tripods caused erratic and noisy conditions.

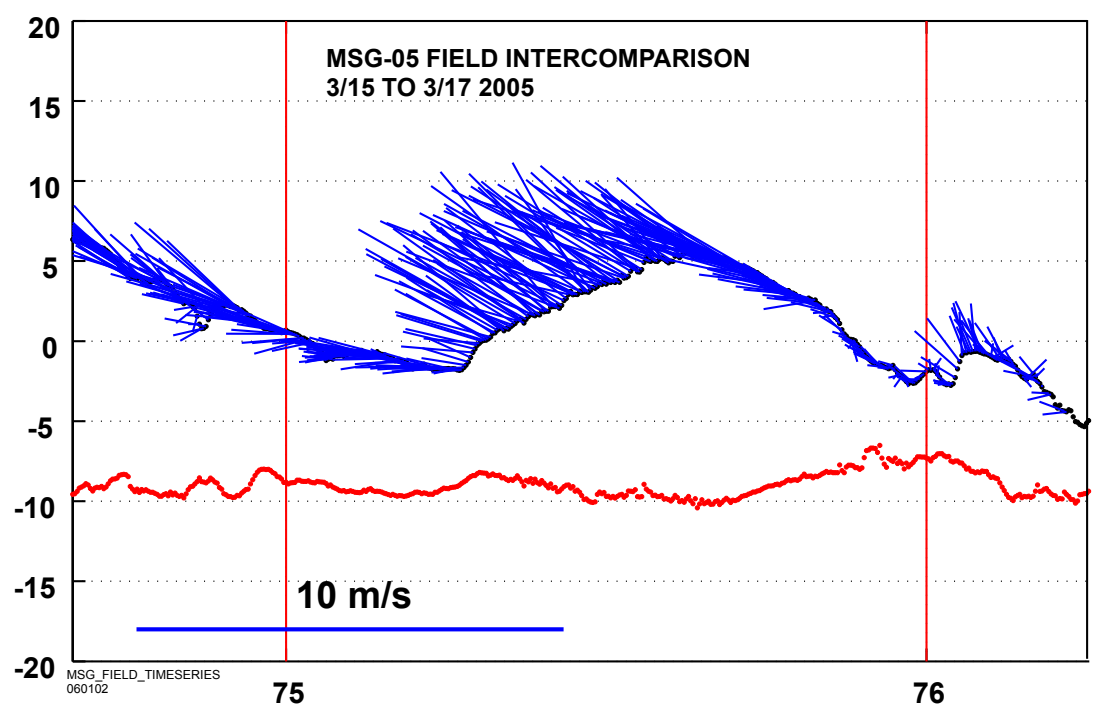

Figure 11: Mean wind speeds during the field intercomparison. shown are plots of air temperature and dew point (red). Superimposed on the temperature plot are wind vectors. The sticks are oriented towards the wind meteorological direction. The beginning 24 hours of the comparison had NW winds.

Table 9: Results from the field intercomparison of the street stations. Street stations included in this study are S1, S2, S3, S4, S5, and S7. A suffix ' $r$ ' signifies an RMY 3D anemometer and a suffix 'w' signifies a WXT510.

\begin{tabular}{|ll|llllllll|}
\hline & & $\mathrm{s} 1 \mathrm{r}$ & $\mathrm{s} 1 \mathrm{w}$ & $\mathrm{s} 2 \mathrm{w}$ & $\mathrm{s} 3 \mathrm{w}$ & $\mathrm{s} 4 \mathrm{r}$ & $\mathrm{s} 4 \mathrm{w}$ & $\mathrm{s} 5 \mathrm{r}$ & $\mathrm{s} 7 \mathrm{r}$ \\
\hline spd & $\mathrm{mn}$ & -0.01 & -0.06 & -0.00 & -0.14 & -0.09 & -0.16 & -0.02 & 0.48 \\
& $\mathrm{std}$ & 0.09 & 0.07 & 0.05 & 0.04 & 0.07 & 0.07 & 0.07 & 0.24 \\
\hline vsp & $\mathrm{mn}$ & 0.07 & 0.02 & 0.08 & -0.07 & -0.03 & -0.08 & 0.03 & 0.58 \\
& $\mathrm{std}$ & 0.07 & 0.06 & 0.04 & 0.05 & 0.06 & 0.08 & 0.04 & 0.29 \\
\hline vdir & $\mathrm{mn}$ & -0.24 & -1.29 & 4.65 & -0.62 & -0.78 & -4.61 & 0.90 & 13.57 \\
& $\mathrm{std}$ & 2.86 & 3.04 & 1.70 & 16.14 & 3.06 & 12.04 & 2.00 & 14.07 \\
\hline sigth & $\mathrm{mn}$ & 0.29 & 0.20 & -1.27 & 1.30 & 2.05 & 1.38 & 1.90 & -5.85 \\
& std & 1.93 & 2.53 & 1.41 & 2.85 & 1.90 & 3.45 & 1.77 & 7.92 \\
\hline
\end{tabular}

Notes: The RMY3D at Sr showed poor behavior. The alignment in the field was unusually large and there seems to be a high noise in the measurements. The overall effect in mean speed and $\sigma_{\theta}$, while large, are still usable. 


\subsection{Sodar Data Evaluation}
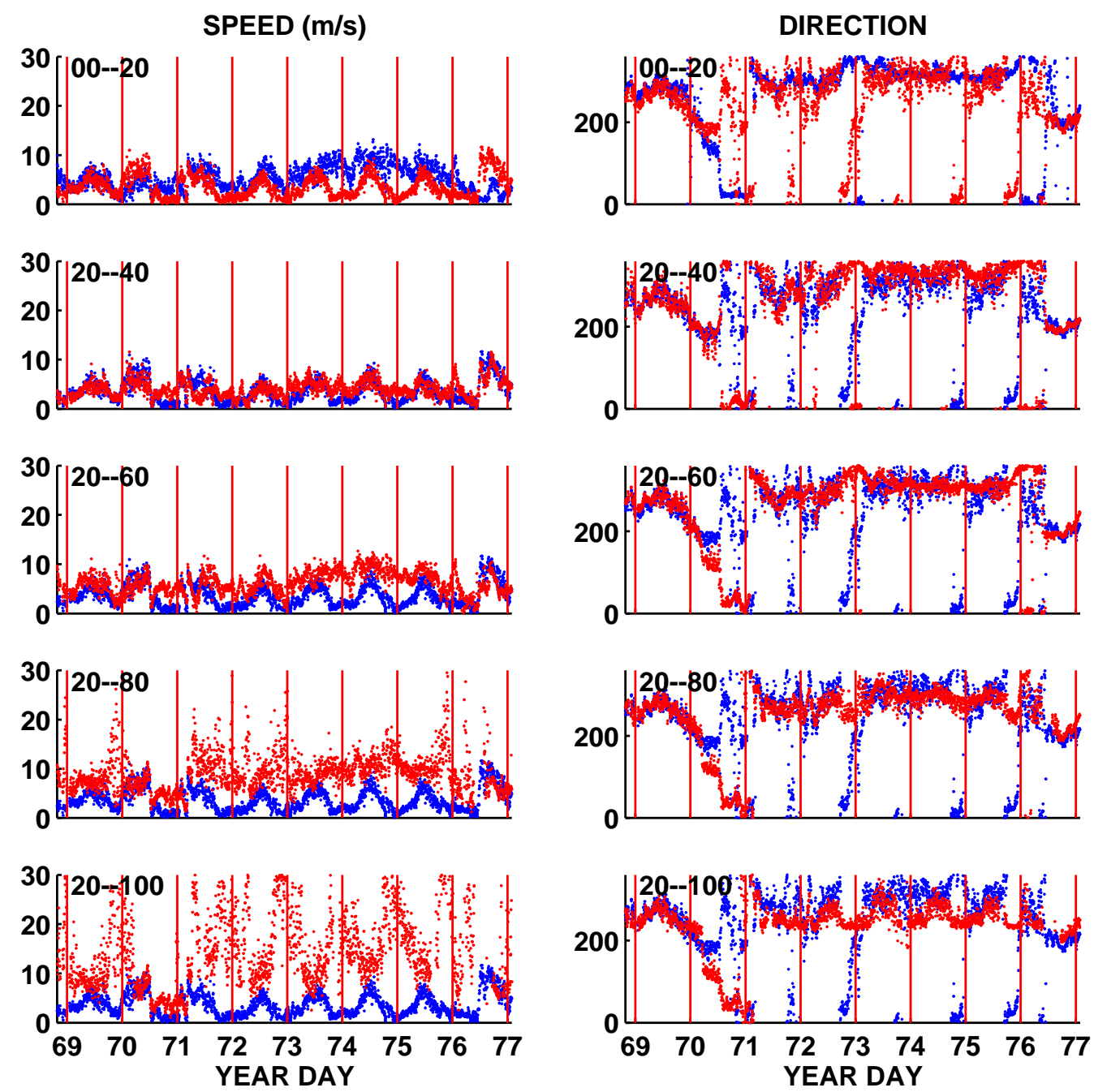

Figure 12: Sodar and met data from SIT. The IOPs took place on the mornings of Julian days 69 and 73 . The wind speeds and directions measured by the sodar show a marked change at heights above about $60 \mathrm{~m}$. Wind speeds became quite strong while directions were consistent throughout. There is some question whether this is an artifact of noise or is real. 

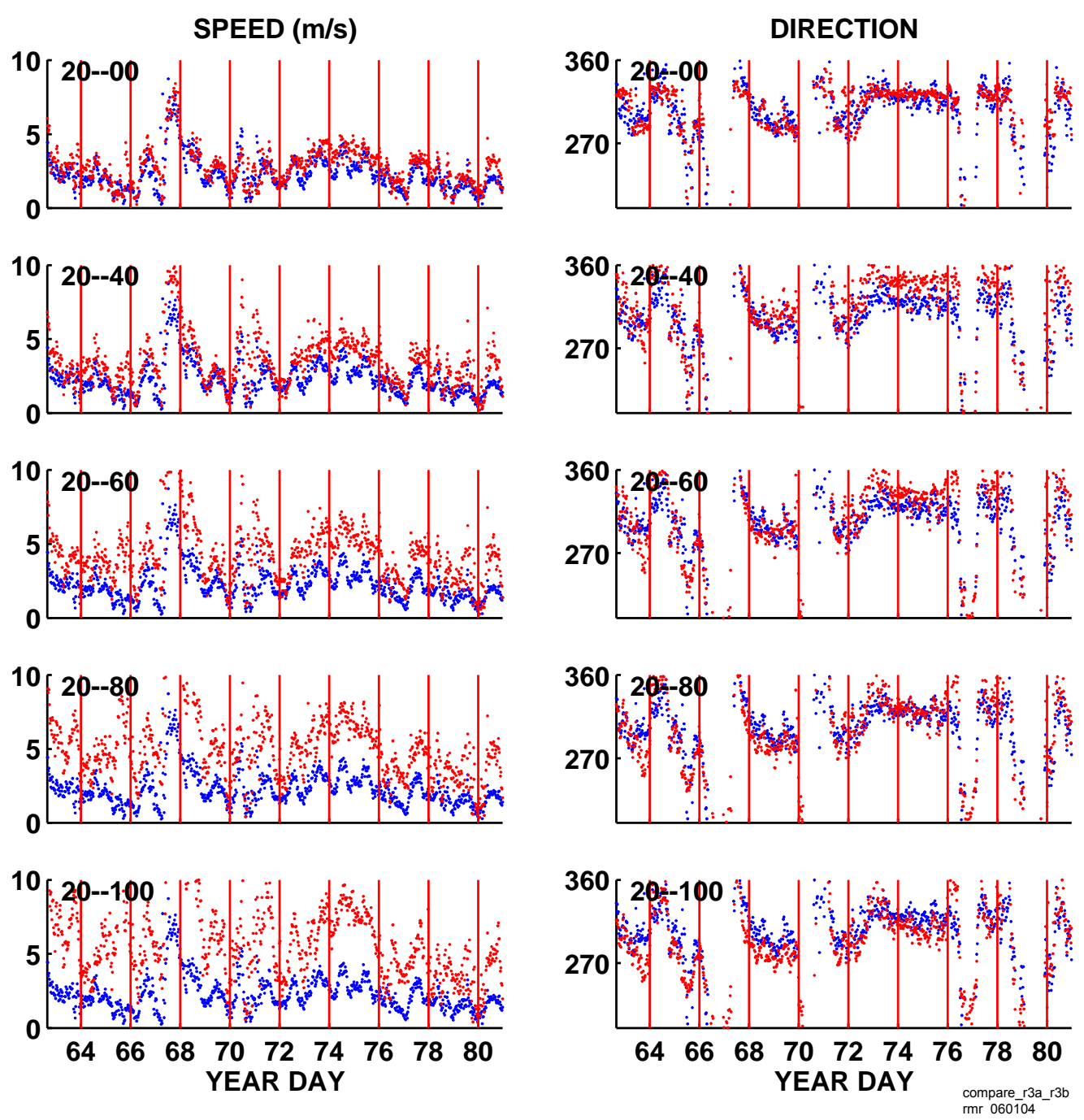

Figure 13: Sodar and met data from Farley Post Office. The IOPs took place on the mornings of Julian days 69 and 73. The wind speeds and directions measured by the sodar show a marked change at heights above about $60 \mathrm{~m}$. These results are much better behaved than the SIT data in figure 12 . 


\section{The MSG05 Meteorological Team}

Bill Behrens Digital interfaces and web dissemination

Victor Cassella Meteorological Forecasting and mesonet liason

Ray Edwards Electronic engineering and field support

Scott Smith Instrument fabrication, street station logistics. 


\section{References}

\section{References}

Allwine, J. (2004). Field work plan—new york city - urban dispersion program madison square garden field study. Compiled from various authors as a complete operational overview. MSG04 plan final a.pdf.

Anderson, P. (2001). What is sodar? In http://www.antarctica.ac.uk.

Beran, D. (1970). Applications of acoustics in meteorology. Project EAR final Reports Report II, University of Melbourne, Department of Meteorology.

Clifford, S., Kaimal, J., Lataitis, R., and Strauch, R. (1994). Groundbased remote profiling in atmospheric studies: An overview. Proc. IEEE, 82:313-355.

Crescenti, G. H. (1998). The degredation of doppler SODAR performance due to noise: a review. Atmos. Environ., 326(9005):1499-1509.

Crescenti, G. H. and Baxter, R. (1998). Examples of noise interference on doppler sodar interference. In Tenth Symposium on Meteorological Observations and Instrumentation, Phoenix AZ, Jan 11-16 Observations and Instrumentation, Phoenix, AZ, Jan. 1116, pages 228-232, Boston , MA. American Meteorological Society, American Meteorological Society. Preprint.

Fleming, H. E. and Hill, M. L. (1982). An objective procedure for detecting and correcting errors in geophysical data: 1. onedimensional applications. Jour. Geophys. Res., 87(C9):7312-7324.

Gaynor, J. (1977). Acoustic doppler measurement of atmospheric boundary layer velocity structure functions and energy dissipation rates. Jour. Appl. Meteor., 160:148-155.

Hanna, S., Reynolds, R., Heiser, J., and Bornstein, R. (2004). Plans for msg04 tracer experiment in manhattan. Paper 1.5 at AMS Urban Environment Conference, Vancouver. Available at AMS web site (www.ametsoc.org) and on CD from AMS, 45 Beacon St., Boston, MA 02215.

Kallistratova, M. (1961). Experimental investigations of sound wave scattering in the atmosphere. Trudy instituta fizika at atmosfery, Atmosfernaya Turbulentnost, 43:203-256.

Little, C. G. (1969). Acoustic methods of remote probing of the lower atmosphere. Proc. IEEE, 57(4).

McAllister, L., Pollard, J., Mahoney, A., and Shaw, P. (1968). A new approach to the study of atmospheric structure. Technical Report CPD(T) 160, Australian Weapons Research Establishment, Salisbury, S. Australia.

Monin, A. (1962). Characteristics of the scattering of sound in a turbulent atmosphere. Soviet physicsAcoustics, 7(4):370-373. Translated from Akusticheskii Zhurnal, 7, 4, 457-461, 1961.

Neff, W. and Coulter, R. (1986). Acoustic remote sensing. In Lenshow, D., editor, Probing the Atmospheric Boundary Layer, pages 201-239. Amer. Meteor. Soc.

Reynolds, M. (1970). The design and construction of an acoustic sounder. In Radok, U., editor, Project EAR (Environmental Acoustic Research, technical report III. University of Melbourne, Meteorology Department, Melbourne Victoria Australia.

Reynolds, R. M. (2005). The Madison Square Garden Dispersion Study (MSG05). meteorological data report part 2: Instrumentation. In preparation for data archival.

Schwieson, R. (1986). A comparitive overview of active remotesensing techniques. In Lenshow, D., editor, Probing the Atmospheric Boundary Layer. Amer. Meteor. Soc.

Taylor, J. R. (1982). An Introduction to Error Analysis. University Science Books, Oxford University Press.

Watson, T. (2005). Madison square garden 2005 pft tracer study, tracer data report. Preliminary data report for the tracer program in MSG-05. 


\section{A R. M. Young Model 81000 3D Sonic Anemometer}

\section{YOUNG}

\section{Model 81000 Ultrasonic Anemometer}

The YOUNG Model 81000 Ultrasonic Anemometer is a 3-axis, no moving parts wind sensor. It is perfectly suited for applications requiring fast response, high resolution and threedimensional wind measurement.

The sensor features durable, corrosion-resistant construction with 3 opposing pairs of ultrasonic transducers supported by stainless steel members. The transducers are arranged so that measurements are made through a common volume. A fast, 160 $\mathrm{Hz}$ internal sampling rate ensures superior measurement resolution. Output rates from 4 to $32 \mathrm{~Hz}$

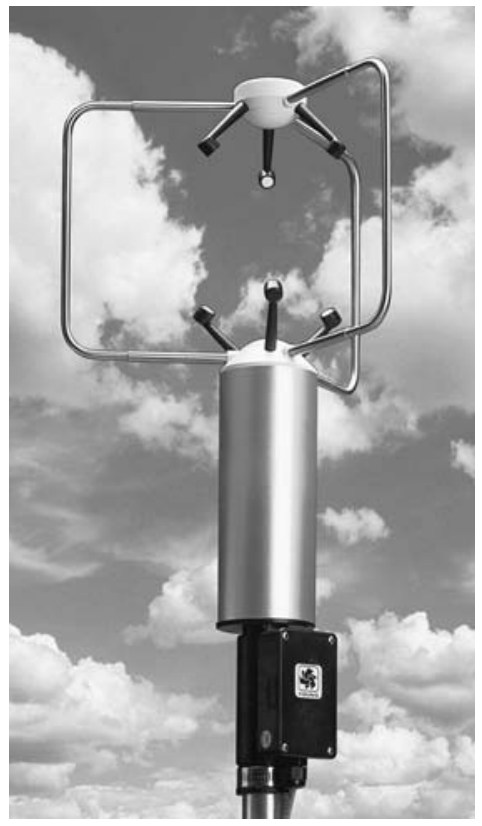
may be selected. Each 81000 is individually wind-tunnel tested and calibrated to compensate for wind shadow effects of the support structure.

Model $\mathbf{8 1 0 0 0}$ features four voltage ouput channels. Serial RS-232 and RS-485 outputs are available as well. For applications requiring synchronized analog measurements, Model $\mathbf{8 1 0 0 0 V}$ includes four voltage input channels instead of voltage outputs. Wind, sonic temperature and voltage input data are transmitted serially. For each model, a variety of preset or custom output format options may be selected by the user.

Both models install on standard 1 inch pipe. Wiring connections are housed in a convenient weatherproof junction box.

Ordering Information MODEL

ULTRASONIC ANEMOMETER- VOLTAGE \& SERIAL OUTPUTS .... 81000 ULTRASONIC ANEMOMETER- VOLTAGE INPUTS, SERIAL OUTPUTS ONLY.......81000V

\section{Specifications}

Wind Speed: 0 to $40 \mathrm{~m} / \mathrm{s}$ ( 0 to $90 \mathrm{mph}$ ) Resolution: $0.01 \mathrm{~m} / \mathrm{s}$

Threshold: $0.01 \mathrm{~m} / \mathrm{s}$

Accuracy: $\pm 1 \% \mathrm{rms} \pm 0.05 \mathrm{~m} / \mathrm{s}(0$ to $30 \mathrm{~m} / \mathrm{s})$ $\pm 3 \% \mathrm{rms}(30$ to $40 \mathrm{~m} / \mathrm{s})$

Wind Direction: 0 to 360 degrees

Elevation Range: \pm 60 degrees

Resolution: 0.1 degree

Accuracy: \pm 2 degrees ( 1 to $30 \mathrm{~m} / \mathrm{s}$ )

\pm 5 degrees ( 30 to $40 \mathrm{~m} / \mathrm{s}$ )

Speed of Sound: 300 to $360 \mathrm{~m} / \mathrm{s}$

Resolution: $0.01 \mathrm{~m} / \mathrm{s}$

Accuracy: $\pm 0.1 \% \mathrm{rms} \pm 0.05 \mathrm{~m} / \mathrm{s}(0$ to $30 \mathrm{~m} / \mathrm{s}$ )

Sonic Temperature: -50 to $+50^{\circ} \mathrm{C}$

Resolution: $0.01^{\circ} \mathrm{C}$

Accuracy: $\pm 2{ }^{\circ} \mathrm{C}(0$ to $30 \mathrm{~m} / \mathrm{s})$

\section{Serial Output:}

RS-232 or RS-485

1200 to 38400 baud

4 to $32 \mathrm{~Hz}$ (user-selected)

User Programmable ASCII output configuration

(select from U, V, W, Speed of sound, Sonic

temperature, 2D speed, 3D speed, Azimuth,

Elevation)

Preset outputs:

NMEA- Marine Standard

RMYT- Young Wind Tracker

Units: $\mathrm{m} / \mathrm{s}, \mathrm{cm} / \mathrm{s}, \mathrm{MPH}$, Knots, Km/hr

Analog Voltage Outputs (81000):

4 voltage outputs, 0 to $5000 \mathrm{mV}$

(select from U, V, W, Sonic temperature or

Speed, Azimuth, Elevation, Sonic temperature)

Voltage Input (81000V):

Range: 0 to $5000 \mathrm{mV}, \mathrm{V} 1 \&$ V2

0 to $1000 \mathrm{mV}, \mathrm{V} 3 \&$ V4

Resolution: 1 part in 4000

Accuracy: $\pm 0.1 \%$ of full scale

Power Requirement:

12 to 24 VDC, $110 \mathrm{~mA}$

Operating Temperature:

-50 to $+50^{\circ} \mathrm{C}$

Dimensions:

$56 \mathrm{~cm}$ high $\times 17 \mathrm{~cm}$ radius ( 3 support arms)

Weight: $1.7 \mathrm{~kg}(3.8 \mathrm{lb})$

Shipping Weight: $4.5 \mathrm{~kg}(10 \mathrm{lb})$ 


\section{B WXT510}

WXT510

WEATHER MULTI-SENSOR

\section{Technical Data}

\section{Operating Principle}

Vaisala WINDCAP' Sensor

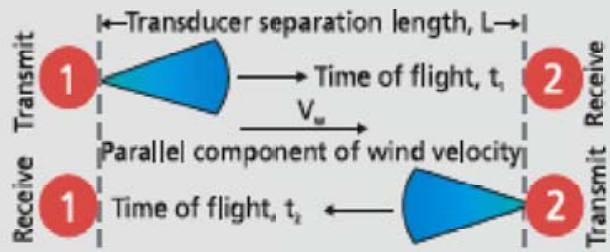

For static speed of sound $V_{;} \frac{1}{t_{1}}=\frac{V_{1}+V_{\text {r }}}{L}$ and $\frac{1}{t_{4}}=\frac{V_{1}-V_{2}}{l}$

Combine to remove $V_{i} \quad V_{n}=\frac{l}{2}\left(\frac{1}{t_{1}}+\frac{1}{t_{1}}\right)$
Solve for $V_{\infty}$

Time-offlight for a sonic impulse fram the transmit tran stueer to the rec eive transducer is determined for both directions. Simple algetra allowa sabving for the parallid component of wind vilocity indegendently of the static speed of sound.
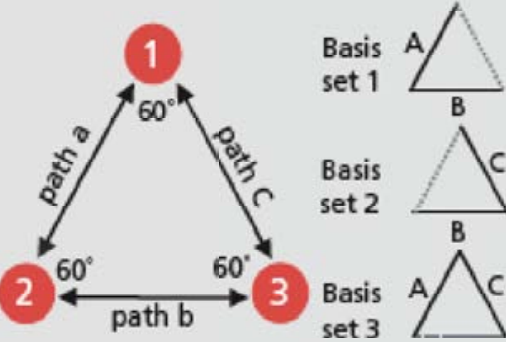

The equilateral triangle canfiguration of the three transalucess provides thre pasrible sets of basis vectorn. The combinations yild bi-directional measurcments on the paths labolad $A, B$ and $C$. These measursments ane used to datemine the wind velocity conponents parallal to aach of the three paths.

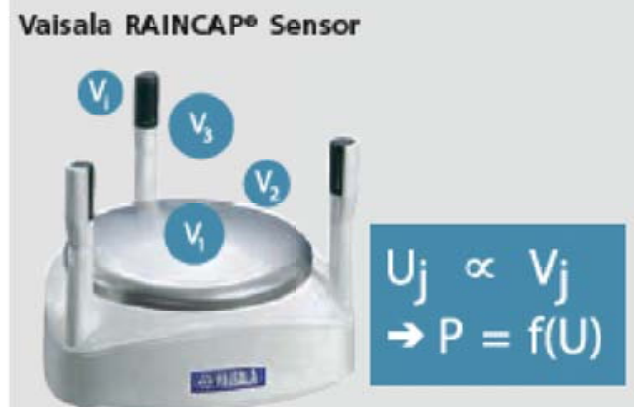

The precipitation sonvor detects the impact of individaal naindrops. The votage signals $U$, resulting from the impacts are praportiond to the volume of the drogs $V_{1}$ and therofore, the signal of each drap can be directly conserted to accumalated procipitation $P$.

\section{Wind}

\begin{tabular}{|c|c|}
\hline Windspeed & \\
\hline Range & $0.60 \mathrm{~m} / \mathrm{s}$ \\
\hline Response tims & $0.25 a$ \\
\hline Aviablable variables & awrage maximum and minimum \\
\hline Accuracy & $\neq 0.3 \mathrm{~m} / \mathrm{s}$ or $\pm 2 \%$ whichews is greater \\
\hline Output resolution & $0.1 \mathrm{~m} / \mathrm{s}(\mathrm{km} / \mathrm{h}$, ny h $\mathrm{knots})$ \\
\hline Units arailable & $\mathrm{m} / \mathrm{s}, \mathrm{km} / \mathrm{h}, \mathrm{mph}, \mathrm{knots}$ \\
\hline Wind direction & \\
\hline Azimuth & $0.360^{\circ}$ \\
\hline Response time & $250 \mathrm{~ms}$ \\
\hline A vilable wariables & Anorage, maximum and minimum \\
\hline Accuracy & $\pm z$ \\
\hline Outputresolution & $1^{*}$ \\
\hline
\end{tabular}

Output resolution

$1 . .600 \mathrm{~s}$ (= $10 \mathrm{~min})$, at onesscond stops an the basis of 0.25 secand samples Awraging time $1 . .3600 \mathrm{~s}$ (= $60 \mathrm{~min})$ at cos socond staps

Updato intorm

1...3600s $(=60 \mathrm{~min})$ at cos socond stups

\section{Lquild Predpitation}

\section{Rainfal}

Collocting ares

Output resolution

Accuracy

Units arailable

Rain duration

Output resolution

Rain intensity

Range

Output resolution Units avilable

Hail

Output vesolution

Units araiable

Hail duration

Hail intensity Output rosolution Units arailable
Output resolution

cumulatio accumulation after latest autecnatic or manual neset $0.01 \mathrm{~mm}(0.001 \mathrm{in})$ 5** $\mathrm{mm}$, in 103 one minute running arerage in tsa second stops a. $200 \mathrm{~mm} / \mathrm{h}$ (broador range with roduced accuracy)

$$
0.1 \mathrm{~mm} / \mathrm{h}(0.01 \mathrm{ia} / \mathrm{h})
$$

cumulative amount of hits against collocting surface 0.1 hits $/ \mathrm{cm}^{2}\left(1\right.$ hits/in $\left.{ }^{2}\right)$ hits/ $\mathrm{cm}^{2}$, hita/in', hits

counting each ton socend incremsnt whenewer hailstooe dstected

one minute running aver aze in ton second stops 0.1 bits/cmth $(1$ hits/in'th) hita/car'h, hits/in'th, hits/b

- Dus to the nature of the plepornencen deriations caused by spatial variations mayexist in precipitation resdings especially in short ime scals. The accuracy spocif cation does not include possible sind induced strec.

PTU module = Barometric Pressure, Alr Temperature and Relative Humidity

\section{Barometric Pressure}

Range

Accuracy 


\section{Technical Data, Dimensions}

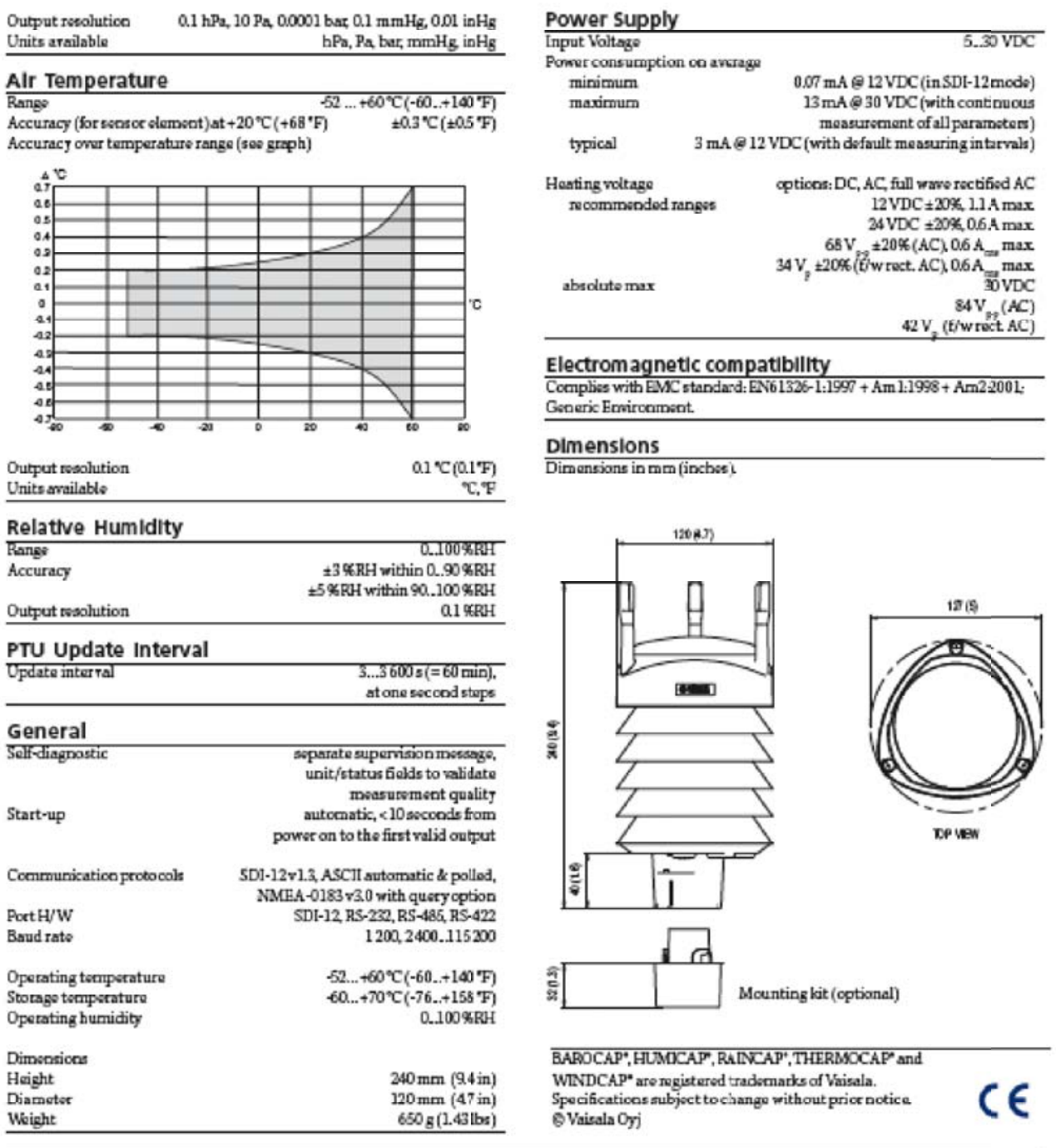

Vaisala Oyj. P.O. Box 26, FIN-00421 Helsinki. FINLAND Teli +358989491 . Faxi +358989492485

Emaili weather.transmitter vaisala.com

Please look for other locations at worw.vaisalacom 


\section{SODAR Raw Data Block}

\begin{tabular}{|c|c|c|c|c|c|c|c|c|c|c|c|c|c|c|c|c|c|c|c|}
\hline NYCOOC & 08 & $109 / 2$ & 00 & $: 03 \mathrm{TC}$ & $08 / C$ & 12003 & $00: 1$ & V & & & 800 & 100 & 50 & 10 & 0 & & & & \\
\hline 60 & $\begin{array}{llll}0 & 7 & -1\end{array}$ & 200 & 10 & 960 & $55-$ & & $0-80$ & 800 & 40 & & ro & 681 & 390 & 00 & & & & & \\
\hline $\mathrm{COM}$ & PONENT & $40 \mathrm{HT}$ & ZENITH & $16-16$ & ARA & $06 \mathrm{SEP}$ & ANG $C$ & МXHT & 0 & ISE & 14 & $3 \mathrm{VNO}$ & ISE & 15 WN & & 135 & & & \\
\hline ITEI & NA STAT & $\Gamma$ & $T A C$ & TATU & $\mathrm{OFF}$ & BATTV & 3.931 & & & & & & & & & & & & \\
\hline HT & SPD & DIR & W & SDW & IW & GSPD & GDIR & $\mathrm{U}$ & SDU & NU & IU & SNRU & V & SDV & NV & IV & SNRV & NW & SNRW \\
\hline 200 & 99.99 & 9999 & 99.99 & 99.99 & 130 & 99.99 & 9999 & 99.99 & 99.99 & 0 & 144 & 2 & 99.99 & 99.99 & 0 & 115 & 2 & 0 & 3 \\
\hline 195 & 99.99 & 9999 & 99.99 & 99.99 & 141 & 99.99 & 9999 & 99.99 & 99.99 & 0 & 135 & 2 & 99.99 & 99.99 & 0 & 110 & 2 & 0 & \\
\hline 190 & 99.99 & 9999 & 99.99 & 99.99 & 144 & 99.99 & 9999 & 99.99 & 99.99 & 0 & 131 & 2 & 99.99 & 99.99 & 0 & 109 & 2 & 0 & \\
\hline 185 & 99.99 & 9999 & 99.99 & 99.99 & 137 & 99.99 & 9999 & 99.99 & 99.99 & 0 & 129 & 2 & 99.99 & 99.99 & 0 & 104 & 2 & 0 & \\
\hline 180 & 99.99 & 9999 & 99.99 & 99.99 & 145 & 99.99 & 9999 & 99.99 & 99.99 & 0 & 144 & 2 & 99.99 & 99.99 & 0 & 101 & 0 & 0 & \\
\hline 175 & 99.99 & 9999 & 99.99 & 99.99 & 142 & 99.99 & 9999 & 99.99 & 99.99 & 0 & 131 & 2 & 99.99 & 99.99 & 0 & 108 & 2 & 0 & \\
\hline 170 & 99.99 & 9999 & 99.99 & 99.99 & 131 & 99.99 & 9999 & 99.99 & 99.99 & 0 & 121 & 2 & 99.99 & 99.99 & 0 & 101 & 2 & 0 & \\
\hline 165 & 99.99 & 9999 & 99.99 & 99.99 & 141 & 99.99 & 9999 & 99.99 & 99.99 & 0 & 124 & 2 & 99.99 & 99.99 & 0 & 99 & 2 & & \\
\hline 160 & 99.99 & 9999 & 99.99 & 99.99 & 136 & 99.99 & 9999 & 99.99 & 99.99 & 0 & 130 & 2 & 99.99 & 99.99 & 0 & 116 & & & \\
\hline 155 & 99.99 & 9999 & 99.99 & 99.99 & 136 & 99.99 & 9999 & 99.99 & 99.99 & 0 & 121 & 2 & 99.99 & 99.99 & 0 & 109 & & & \\
\hline 150 & 99.99 & 9999 & 99.99 & 99.99 & 129 & 99.99 & 9999 & 99.99 & 99.99 & 0 & 120 & 2 & 99.99 & 99.99 & 0 & 100 & & & \\
\hline 145 & 99.99 & 999 & 99.99 & 9.99 & 130 & 99.99 & 9999 & 99.99 & 99.99 & 0 & 120 & 2 & 99.99 & 99.99 & 0 & 96 & & & \\
\hline 140 & 99.99 & 999 & 99.99 & 9.99 & 124 & 99.99 & 9999 & 99.99 & 99.99 & 0 & 115 & 2 & 99.99 & 99.99 & 0 & 93 & & & \\
\hline 135 & 99.99 & 999 & 99.99 & 9.99 & 122 & 99.99 & 9999 & 99.99 & 99.99 & 0 & 105 & 2 & 99.99 & 99.99 & 0 & 90 & & & \\
\hline 130 & 99.99 & 999 & 99.99 & 9.99 & 122 & 99.99 & 9999 & 99.99 & 99.99 & 0 & 107 & 2 & 99.99 & 99.99 & 0 & 79 & & & \\
\hline 125 & 99.99 & 999 & 99.99 & 9.99 & 116 & 99.99 & 9999 & 99.99 & 99 & 0 & 121 & 3 & 99.99 & 99.99 & 0 & 86 & & & 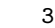 \\
\hline 120 & 99.99 & 9999 & 99.99 & 99.99 & 113 & 99.99 & 9999 & 99.99 & 99.99 & 2 & 134 & 4 & 99.99 & 99.99 & 0 & 85 & 4 & 0 & 3 \\
\hline 115 & 99.99 & 999 & 99.99 & 99.99 & 122 & 99.99 & 9999 & 99.99 & 99.99 & 1 & 127 & 4 & 99.99 & 99.99 & 0 & 82 & 4 & 0 & 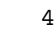 \\
\hline 110 & 99.99 & 9999 & 99.99 & 99.99 & 127 & 99.99 & 9999 & 99.99 & 99.99 & 8 & 144 & 4 & 99.99 & 99.99 & 0 & 94 & 4 & 0 & 4 \\
\hline 105 & 99.99 & 9999 & 99.99 & 99.99 & 119 & 99.99 & 9999 & 99.99 & 99.99 & 2 & 146 & 4 & 99.99 & 99.99 & 2 & 101 & 4 & & 4 \\
\hline 100 & 8.65 & 218 & 99.99 & 99.99 & 124 & 9.88 & 218 & 4.53 & 0.14 & 3 & 141 & 4 & 7.37 & 0.38 & 3 & 109 & 4 & & 4 \\
\hline 95 & 99.99 & 9999 & 1.10 & 0.22 & 132 & 8.92 & 223 & 3.98 & 0.32 & 4 & 136 & 4 & 99.99 & 99.99 & 2 & 110 & 4 & & \\
\hline 90 & 99.99 & 9999 & 1.05 & 0.48 & 149 & 4.83 & 214 & 1.38 & 0.46 & 5 & 157 & 6 & 99.99 & 99.99 & 1 & 116 & & & \\
\hline 85 & 4.66 & 201 & 1.24 & 0.40 & 152 & 10.01 & 199 & 1.24 & 0.48 & 7 & 171 & 6 & 4.49 & 0.15 & 3 & 126 & $\epsilon$ & & \\
\hline 80 & 5.57 & 210 & 1.20 & 0.42 & 160 & 8.55 & 204 & 2.29 & 0.55 & 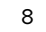 & 18 & r & 5.08 & 0.37 & 9 & 142 & 7 & & \\
\hline 75 & 3.16 & 200 & 0.91 & 0.35 & 183 & 7.24 & 238 & 0.79 & 0.43 & 8 & 193 & 8 & 3.06 & 0.47 & 10 & 146 & 8 & 12 & 8 \\
\hline 70 & 2.60 & 197 & 0.84 & 0.48 & 199 & 10.32 & 227 & 0.49 & 0.49 & 10 & 223 & 9 & 2.55 & 0.51 & 11 & 155 & 9 & 13 & 9 \\
\hline 65 & 3.24 & 201 & 0.65 & 0.52 & 208 & 7 & 219 & 0.82 & 8 & 13 & 253 & 11 & 3.13 & 0.55 & 11 & 171 & 11 & 14 & 10 \\
\hline 60 & 2.77 & 207 & 0.62 & 0.46 & 254 & 5.90 & 224 & 0.99 & 0.42 & 14 & 244 & 11 & 2.59 & 0.75 & 11 & 180 & 11 & 15 & 12 \\
\hline 55 & 2.69 & 205 & 0.51 & 0.40 & 274 & 5.28 & 228 & 0.88 & 0.28 & 14 & 232 & 10 & 2.55 & 0.61 & 14 & 197 & $=0$ & 15 & 12 \\
\hline 50 & 3.08 & 208 & 0.40 & 0.47 & 333 & 6.10 & 233 & 1.14 & 0.49 & 13 & 278 & 12 & 2.86 & 0.40 & 14 & 224 & 2 & 15 & 15 \\
\hline 45 & 2.84 & 207 & 0.28 & 0.53 & 344 & 5.00 & 213 & 1.02 & 0.41 & 15 & 363 & 16 & 2.64 & 0.50 & 15 & 248 & 16 & 15 & 16 \\
\hline 40 & 3.78 & 217 & 0.12 & 0.61 & 305 & 6.66 & 231 & 1.96 & 0.46 & 14 & 447 & 18 & 3.23 & 0.35 & 14 & 250 & 18 & 15 & 15 \\
\hline 35 & 3.83 & 221 & 0.07 & 0.59 & 296 & 6.41 & 216 & 2.22 & 0.50 & 15 & 489 & 17 & 3.12 & 0.36 & 15 & 274 & 17 & 15 & 17 \\
\hline 30 & 3.27 & 222 & 0.06 & 0.45 & 318 & 5.83 & 224 & 1.91 & 0.45 & 15 & 432 & 16 & 2.65 & 0.25 & 15 & 283 & 16 & 15 & 14 \\
\hline 25 & 1.58 & 265 & 0.02 & 0.24 & 627 & 2.71 & 269 & 1.55 & 0.33 & 15 & 517 & 18 & 0.31 & 0.15 & 15 & 797 & 18 & 15 & 16 \\
\hline 20 & 0.77 & 242 & 0.18 & 0.25 & 795 & 2.49 & 234 & 0.64 & 0.30 & 15 & 515 & 16 & 0.43 & 0.15 & 15 & 802 & 16 & 15 & 31 \\
\hline 15 & 1.20 & 349 & 0.24 & 0.26 & 851 & 2.62 & 309 & 0.35 & 0.30 & 14 & 664 & 13 & -1.15 & 0.32 & 13 & 1239 & 13 & 15 & 20 \\
\hline 10 & 3.95 & 315 & 99.99 & .99 & 437 & 4.65 & 311 & 3.09 & 0.24 & 15 & 1865 & 8 & -2.46 & 0.25 & 15 & 3295 & 8 & 0 & 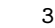 \\
\hline 5 & 4.15 & 313 & 99.99 & 99.99 & 1967 & 4.64 & 334 & 3.32 & 0.18 & 15 & 1820 & 8 & -2.49 & 0.12 & 15 & 3309 & 8 & 0 & 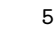 \\
\hline
\end{tabular}




\section{Sodar Header Information}


Table 10: The different terms in the miniSodar header for each time block.

\begin{tabular}{|c|c|}
\hline Line & Site Name \\
\hline $\begin{array}{l}1 \\
2\end{array}$ & Start Date/Time \\
\hline 3 & End Date/Time \\
\hline 4 & SW version \\
\hline 5 & freq \\
\hline 6 & bw \\
\hline 7 & damp \\
\hline 8 & pulw \\
\hline 9 & rise \\
\hline 10 & rofs \\
\hline 11 & jofs \\
\hline Line & \\
\hline 1 & sec \\
\hline 2 & avdst \\
\hline 3 & amp \\
\hline 4 & snr \\
\hline 5 & back \\
\hline 6 & noms \\
\hline 7 & nwt \\
\hline 8 & $\mathrm{gd}$ \\
\hline 9 & nfft \\
\hline 10 & srate \\
\hline 11 & clut \\
\hline 12 & nbini \\
\hline 13 & ngav \\
\hline 14 & mincr \\
\hline 15 & $\operatorname{maxcr}$ \\
\hline 16 & minbr \\
\hline 17 & maxbr \\
\hline 18 & minar \\
\hline 19 & maxar \\
\hline 20 & wdog \\
\hline 21 & mxdel \\
\hline 22 & ptdir \\
\hline 23 & wmax \\
\hline 24 & phase \\
\hline 25 & speci \\
\hline 26 & specl \\
\hline 27 & specm \\
\hline 28 & specn \\
\hline 29 & specs \\
\hline 30 & cdia \\
\hline 31 & cdid \\
\hline 32 & $\operatorname{cdin}$ \\
\hline Line & \\
\hline 1 & Axes \\
\hline 2 & Levels \\
\hline 3 & ZenithV \\
\hline 4 & ZenithU \\
\hline 5 & Rotation \\
\hline 6 & Seperation \\
\hline 7 & mixHt \\
\hline 8 & $\mathrm{rmnU}$ \\
\hline 9 & $\mathrm{rmnV}$ \\
\hline 10 & rmnW \\
\hline 11 & Antenna status \\
\hline
\end{tabular}

Transmit frequency

Filter bandwidth

$\%$ Amplitude level

Transmit pulse width

Pulse shading

In phase offset

Quadrature offset

Wind table time reporting interval

Wind table altitude reporting interval

Fixed amplitude threshold

Signal to Noise threshold

Noise sample collection time

Not used

Not used

Percent good threshold

Number of FFT points

Digital sampling rate

Ground clutter rejection flag

Signal search window

Number of pulses for gust detection

C Beam spectra search limit (lower)

C Beam spectra search limit (upper)

B Beam spectra search limit (lower)

B Beam spectra search limit (upper)

A Beam spectra search limit (lower)

A Beam spectra search limit (upper)

Watchdog timer (enable flag)

Mixing height amplitude detection threshold

Sodar reference fram rotation angle

Vertical velocity detection threshold

Interelement spacing

$\mathrm{S}$ file output interval increment

$\mathrm{S}$ file number of levels output

$\mathrm{S}$ file flag to detail number of axes recorded

$\mathrm{S}$ file number of pulses averages

$\mathrm{S}$ file index of first level recorded

DFS data axis

DFS number of SRATE samples per level

DFS number of pulses per record

Number of active beams

Number of asampling altitudes

Zenith angle of $\mathrm{V}$ beam

Zenith angle of $U$ beam

Sodar antenna rotation angle

Deviation of sodar reference from orthogonal orientation

Detected mixing height

Noise sample for $\mathrm{X}$ beam

Noise sample for $\mathrm{Y}$ beam

Noise sampler for $\mathrm{Z}$ beam

(optional) status of antenna

(optional) of UPS

(Optionally) (optional) anemometer temperature

(optional) ASP battery voltage (DC systems only)
$\mathrm{Hz}$

$\mathrm{Hz}$

millisecond

millisecond

millivolt

millivolt

seconds

meters

millivolt

millisecond

$\%$

$\mathrm{Hz}$

\# points

radial $\mathrm{m} / \mathrm{s}$ radial $\mathrm{m} /$ radial $\mathrm{m} / \mathrm{s}$ radial $\mathrm{m} / \mathrm{s}$ radial $\mathrm{m} / \mathrm{s}$ radial $\mathrm{m} / \mathrm{s}$

millivolt

degrees

$\mathrm{m} / \mathrm{s}$

$\operatorname{deg}$

deg

deg

deg

meters
millivolt

millivolt

millivolt

deg C

0.25 

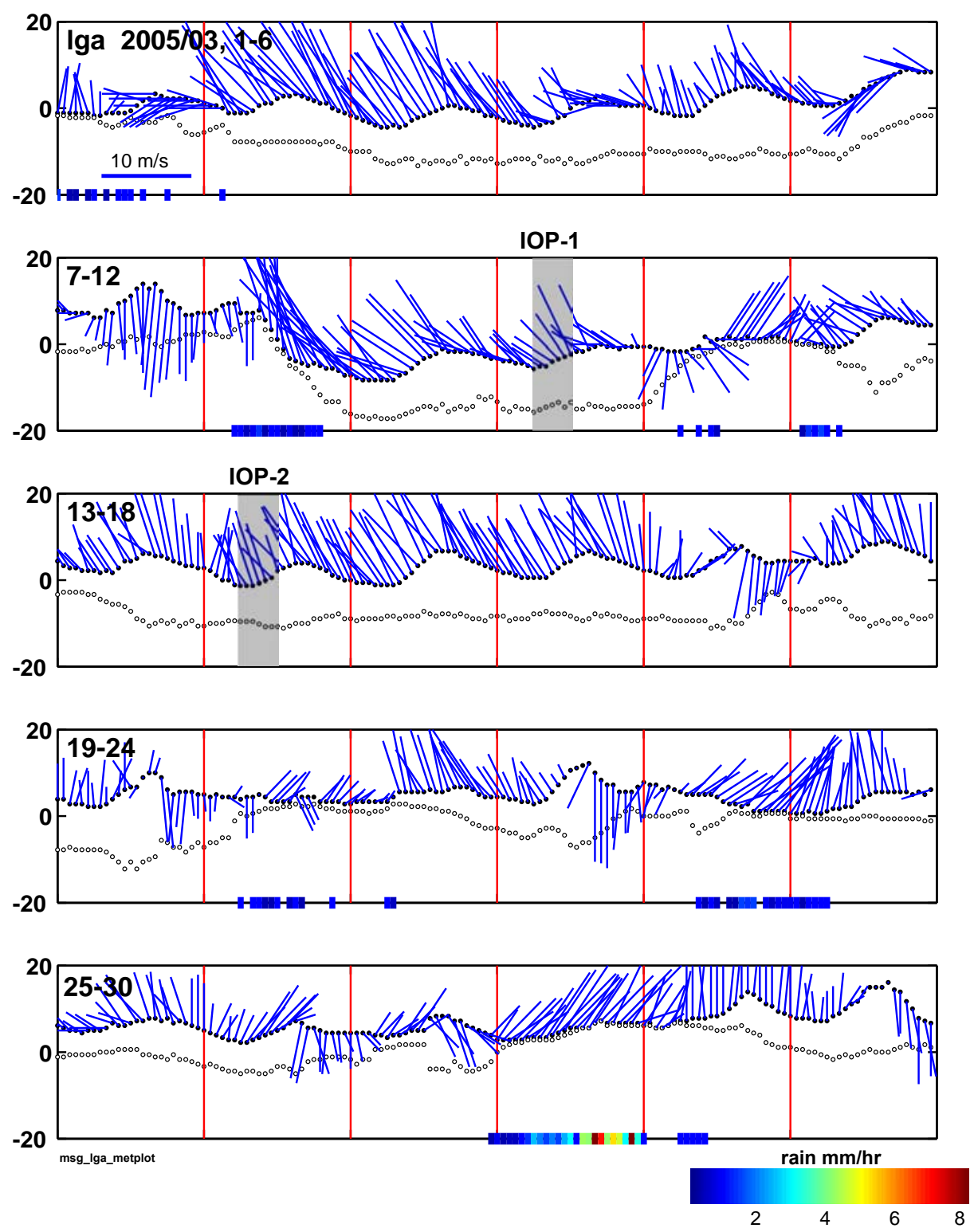

Figure 14: LGA winds for March 2005. 

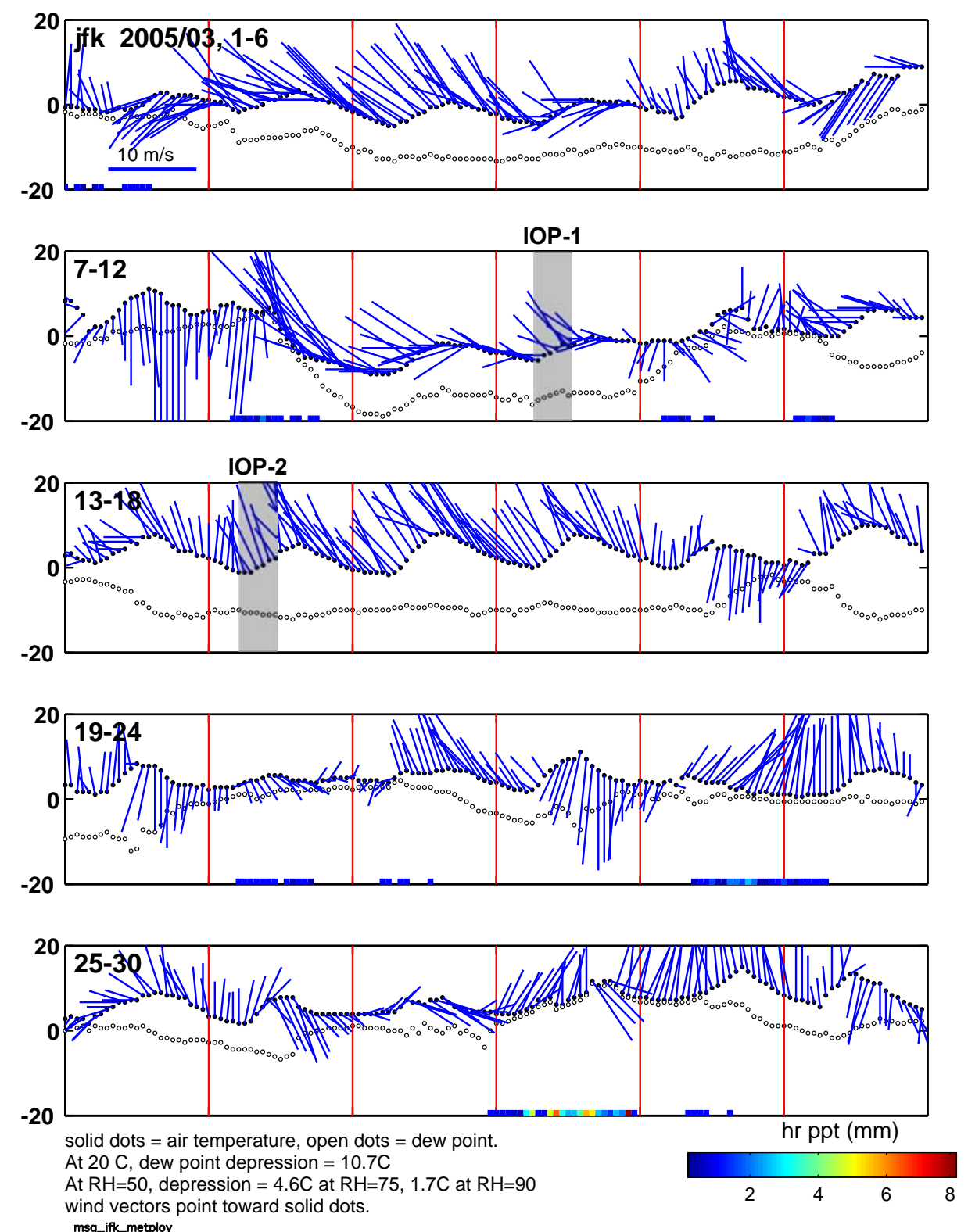

Figure 15: JFK winds for March 2005. 

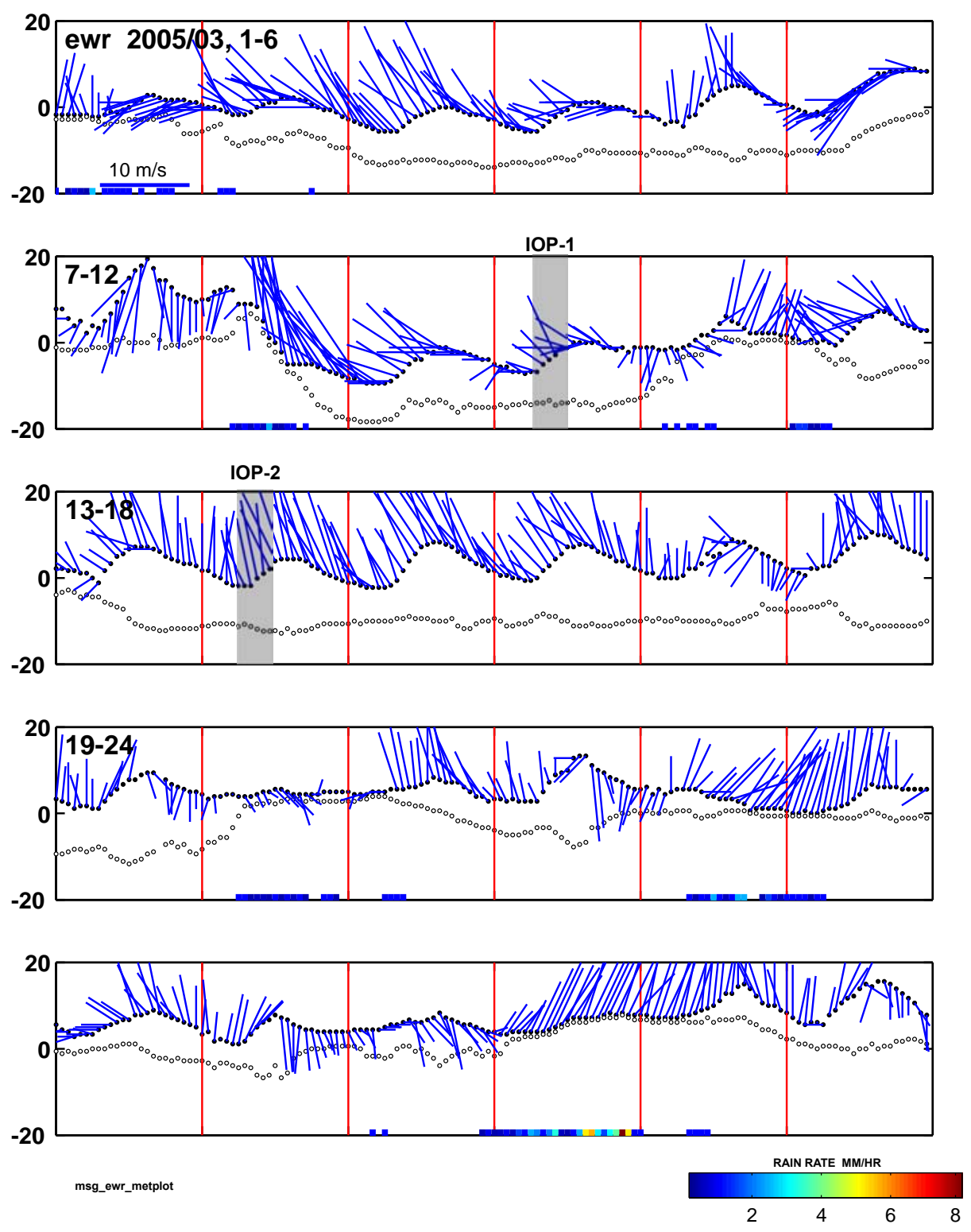

Figure 16: EWR winds for March 2005. 


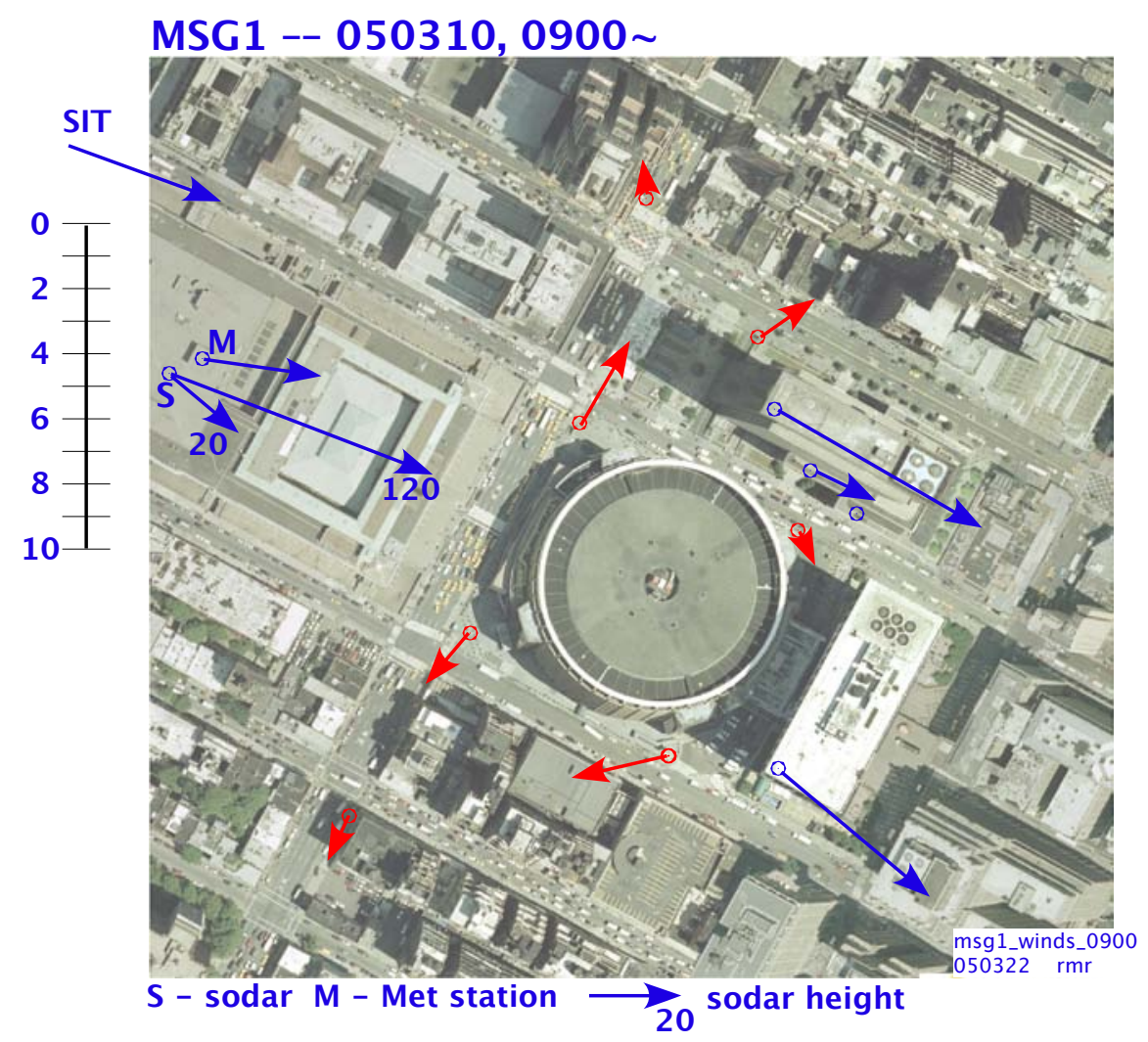

Figure 17: Measured wind fields at 0900 in IOP-1. 


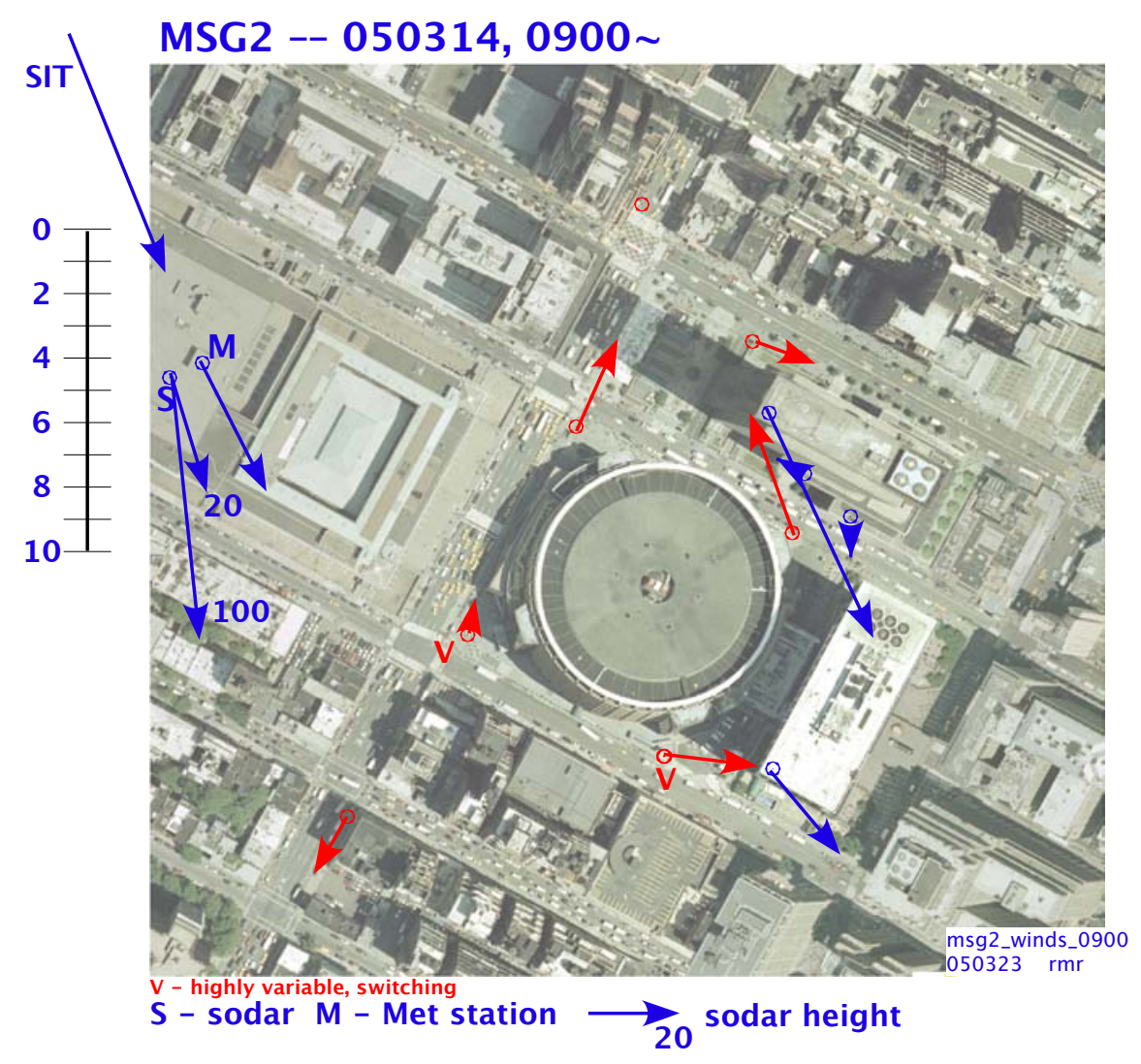

Figure 18: Measured wind fields at 0900 in IOP-2. 